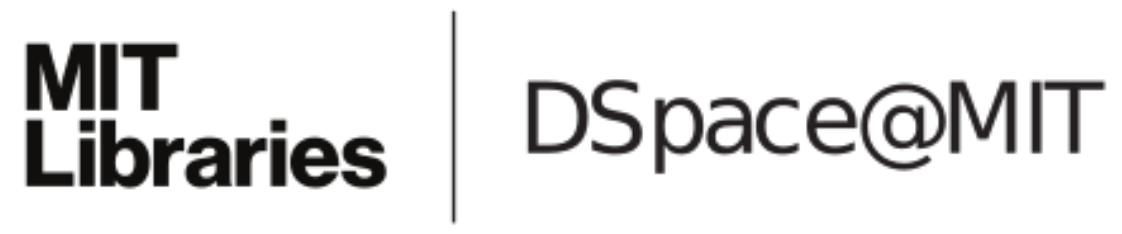

\author{
MIT Open Access Articles
}

\section{Progressive Saturation Improves the Encapsulation of Functional Proteins in Nanoscale Polymer Vesicles}

The MIT Faculty has made this article openly available. Please share how this access benefits you. Your story matters.

Citation: Yewle, Jivan, Paritosh Wattamwar, Zhimin Tao, Eric M. Ostertag, and P. Peter Ghoroghchian. "Progressive Saturation Improves the Encapsulation of Functional Proteins in Nanoscale Polymer Vesicles." Pharmaceutical Research 33, no. 3 (October 27, 2015): 573-589.

As Published: http://dx.doi.org/10.1007/s11095-015-1809-9

Publisher: Springer US

Persistent URL: http://hdl.handle.net/1721.1/103149

Version: Author's final manuscript: final author's manuscript post peer review, without publisher's formatting or copy editing

Terms of Use: Article is made available in accordance with the publisher's policy and may be subject to US copyright law. Please refer to the publisher's site for terms of use. 


\title{
Progressive Saturation Improves the Encapsulation of Functional Proteins in Nanoscale Polymer Vesicles
}

Jivan Yewle ${ }^{1}$, Paritosh Wattamwar ${ }^{1}$, Zhimin Tao ${ }^{2}$, Eric M. Ostertag ${ }^{1}$, and P. Peter Ghoroghchian ${ }^{1,2,3 *}$

1. Vindico Pharmaceuticals, Inc., A169 ASTeCC Bldg., Lexington, Kentucky 40506, United States

2. Koch Institute for Integrative Cancer Research, Massachusetts Institute of Technology, 77 Massachusetts Avenue, Building 76-261F, Cambridge, Massachusetts 02139

3. Dana-Farber Cancer Institute, 450 Brookline Avenue, Boston, Massachusetts, 02115

* To whom correspondence should be addressed: ppg@ mit.edu

\begin{abstract}
Purpose: To develop a technique that maximizes the encapsulation of functional proteins within neutrally charged, fully PEGylated and nanoscale polymer vesicles (i.e. polymersomes).

Methods: Three conventional vesicle formation methods were utilized for encapsulation of myoglobin (Mb) in polymersomes of varying size, PEG length, and membrane thickness. Mb concentrations were monitored by UV-Vis spectroscopy, inductively coupled plasma optical emission spectroscopy (ICPOES) and bicinchoninic acid (BCA) assay. Suspensions were subject to protease treatment to differentiate the amounts of surface-associated vs. encapsulated Mb. Polymersome sizes and morphologies were monitored by dynamic light scattering (DLS) and by cryogenic transmission electron microscopy (cryoTEM), respectively. Binding and release of oxygen were measured using a Hemeox analyzer.
\end{abstract}

Results: Using the established "thin-film rehydration" and "direct hydration" methods, Mb was found to be largely surface-associated with negligible aqueous encapsulation within polymersome suspensions. 
Through iterative optimization, a novel "progressive saturation" technique was developed that greatly increased the final concentrations of $\mathrm{Mb}$ (from $<0.5$ to $>2.0 \mathrm{mg} / \mathrm{mL}$ in solution), the final weight ratio of Mb-to-polymer that could be reproducibly obtained (from $<1$ to $>4 \mathrm{w} / \mathrm{w} \% \mathrm{Mb} /$ polymer), as well as the overall efficiency of $\mathrm{Mb}$ encapsulation (from $<5$ to $>\sim 90 \%$ ). Stable vesicle morphologies were verified by cryo-TEM; the suspensions also displayed no signs of aggregate formation for $>2$ weeks as assessed by DLS. "Progressive saturation" was further utilized for the encapsulation of a variety of other proteins, ranging in size from 17 to $450 \mathrm{kDa}$.

Conclusions: Compared to established vesicle formation methods, "progressive saturation" increases the quantities of functional proteins that may be encapsulated in nanoscale polymersomes.

KEY WORDS: Protein, Encapsulation, Myoglobin, Polymersome, Vesicle

\author{
ABBREVIATIONS \\ BSA: bovine serum albumin \\ BCA: bicinchoninic acid \\ Cryo-TEM: cryogenic transmission electron microscopy \\ DLS: dynamic light scattering \\ $\mathrm{Hb}$ : hemoglobin \\ ICP-OES: inductively coupled plasma optical emission spectroscopy \\ IgG: immunoglobulin $G$ \\ mBlue: methylene blue \\ Mb: myoglobin \\ \%Mb EE: myoglobin encapsulation efficiency \\ $\mathrm{Mb}$ :PBS: volume ratio of myoglobin solution to phosphate-buffered saline \\ metMb: metmyoglobin \\ oxyMb: oxygenated (ferrous) myoglobin \\ PAA: poly(L-amino acid) \\ PAAc: poly(acrylic acid) \\ PCL: poly( $\varepsilon$-caprolactone) \\ PBD: polybutadine \\ PDEAEMA: poly(2-(diethylamino)ethyl methacrylate \\ PDPA: poly(2-(diisopropylamino)ethyl methacrylate)
}


PEG: polyethylene glycol

PEO: polyethylene oxide

PEO-b-PBD: poly(ethylene oxide)-block-poly(1,2 butadiene)

PEM: polymersome-encapsulated myoglobin

PIAT: poly(lisocyanoalanine(2-thiophen-3-yl-ethyl)amide) $)_{50}$

PLA: poly (lactic acid)

PMPC: poly(2-(methacryloyloxy)ethyl phosphorylcholine)

PNIPAM: poly( $\mathrm{N}$-isopropylacrylamide)

PPS: polypropylene sulfide

PSM: polymersome

\section{INTRODUCTION}

Proteins have recently shown outstanding pharmaceutical potential due to their ability to overcome significant limitations associated with traditional small molecule therapies $(1,2)$. When compared to the interaction of a small-molecule with its biological target, protein therapeutics have higher folding energies (typically $\sim 7-20 \mathrm{kcal} / \mathrm{mol}$ ) that allow for the adoption of larger and more precise three-dimensional configurations, which are often required for efficient binding and/or control of complex biological function (3). As such, proteins can achieve superior binding selectivity and more potent on-target activity. Currently, the modest number of macromolecular therapies in use, including the $~ 200$ protein drugs available worldwide, has demonstrated the remarkable potential of functional proteins as new leads in drug development (4-6). Nevertheless, several barriers have hindered the ready development of macromolecules as human therapeutics, including: (i) the difficulty and/or expense of commercial scale production; (ii) biochemical instability that occurs in pathophysiologic environments or with prolonged storage; (iii) short circulatory half-lives; (iv) large steric hindrance that prevents effective tissue penetration; and, (v) risks associated with their potential to promote severe adverse effects, such as immunologic and anaphylactic reactions (5).

To overcome some of these limitations, most pharmaceutical compounds either employ biocompatible polymers (e.g. polyethylene glycol (PEG) or hyaluronic acid) or liposomes (i.e. lipid based vesicles) for protein complexation and in vivo delivery. A vast and expanding body of literature, however, has 
demonstrated that synthetic nanoparticles exhibit superior properties and can enhance drug delivery as compared to these more conventional formulations, which are limited by incomplete PEGylation and/or unstable encapsulation. Among the classes of nanoparticle vehicles, polymersomes, or self-assembled polymer vesicles comprised of amphiphilic block copolymers (7-12), are an emerging nanoscale delivery platform. Possessing thick polymeric membranes, polymersomes enable: (i) facile and stable loading of diverse therapeutic payloads through non-covalent interactions; (ii) improved mechanical stability that is 5-50 greater than that of liposomes or micellar structures constructed from similar molecular weight copolymers; (iii) a rich diversity in biochemical properties, which are imparted by their construction from a variety of copolymer compositions and which include: fully PEGylated surfaces and tunable in vivo circulation times, site-specific targeting, environmental responsiveness, as well as complete biodegradation; and, (iv) economic and large scale production that obviates the need for costly postmanufacturing purification $(7,9,11,13-15)$.

While the incorporation of proteins in long-circulating nanoparticles may enhance their pharmacologic performance and improve their on-target activity, most encapsulation efforts have utilized electrostatic interactions to incorporate a handful of highly anionic proteins (16); others have relied on chemical or genetic modification of the original protein for efficient and reproducible nanoparticle formation (17-21). A major unaddressed challenge, however, is to establish and validate a generalizable method for the incorporation of large quantities of native protein in neutrally charged and/or fully PEGylated nanoparticles, which could be employed to prevent protein deactivation, improve circulatory half-life, achieve tissue localization, and minimize systemic activity (22). Most nanoparticle fabrication techniques also involve the input of thermal, electric, ultrasonic or mechanical energy for particle formation $(8,23$ $25)$; alternative methods use organic co-solvents $(26,27)$. In most cases, these fabrication protocols damage the structure and/or function of the protein, making nanoparticle encapsulation more challenging and obviating its utility (28). 
In the case of polymersomes, several methods have been developed for protein encapsulation, including: 1) rehydration of dry polymer (e.g. the "thin-film rehydration" technique) $(11,29-31)$ or the extrusion of preformed vesicles (e.g. by "hollow-fiber extrusion") in the presence of protein solution (32); 2) "direct hydration" $(22,33)$; and, 3) "electroporation" $(34,35)$. Adopted from the liposome literature and widely employed for the encapsulation of organic small molecules, these methods result in low yields of polymersome-encapsulated protein (e.g. "thin-film rehydration"), are limited to small-scale preparations (<1 mL; e.g. "direct hydration"), and/or are best employed for application with a small number of highly charged proteins (e.g. those amenable to vesicle encapsulation by "electroporation"). While the "hollowfiber extrusion" technique has been used for large-scale preparations of liposome-encapsulated protein (32), elevated temperatures and pressures are required for polymersome formation, which have limited its widespread applicability.

Here, we sought to perform a comparative and quantitative study so as to establish a generalizable method for producing scalable quantities of neutrally charged, fully PEGylated, and nanoscale polymersomes that encapsulate functional proteins. We first examined differences in small molecule and protein encapsulation by employing two related and extensively utilized polymersomes formulations, which were both comprised of diblock copolymers of poly(ethylene oxide)-block-poly(1,2 butadiene) (PEO-b-PBD) but that differed with respect to molecular weight and, ultimately, vesicle membrane thickness (i.e. OB18 and OB2-9) (Table I; $(36,37)$ ). Methylene blue (mBlue; $\mathrm{Mw}=319.85 \mathrm{~g} / \mathrm{mol}$ ) was used as a model small molecule and myoglobin $(\mathrm{Mb} ; \mathrm{Mw}=17,600 \mathrm{Da})$ as a model protein with unique biological function (i.e. oxygen storage and release) (Scheme 1A). Two conventional vesicle formation techniques were preferentially employed for the incorporation of these water-soluble agents within PEO-b-PBD polymersomes: "thin-film rehydration" and "direct-hydration" (Scheme 1B and 1C); a third-technique ("electroporation") produced uniformly poor results and was excluded from further comparisons (Scheme S1, Supplemental Information). 
We compared the encapsulation of mBlue and $\mathrm{Mb}$ in PEO-b-PBD polymersomes, which were generated by each of these different methods, in order to examine differences in the fidelity of small molecule versus protein encapsulation. We also monitored the concentrations and redox states of iron in the heme group of $\mathrm{Mb}$ (by inductively coupled plasma optical emission spectroscopy (ICP-OES) and by ultravioletvisible (UV-Vis) absorption spectroscopy, respectively) in order to verify the encapsulation of intact protein by independent methods; the functional capabilities of the encapsulated $\mathrm{Mb}$ to bind and release oxygen were measured using a Hemox analyzer. Finally, we describe the development of a highly reproducible and scalable "progressive saturation" technique for the efficient generation of polymersomeencapsulated $\mathrm{Mb}$ (PEM) suspensions. The generalizability of this method is further established by utilizing a variety of different proteins, ranging from $17-450 \mathrm{kDa}$ in size.

\section{MATERIALS AND METHODS}

\section{Materials}

PEO(3900)- $b-\mathrm{PBD}(6500)$ (OB18) and $\mathrm{PEO}(1300)-b-\mathrm{PBD}(2500)$ (OB29) were purchased from Polymer Source (Dorval, Quebec, Canada; Table I). Horse skeletal muscle Mb, bovine blood hemoglobin (Hb), bovine serum albumin (BSA), catalase (C), fibrinogen (F), sodium hydrosulfite, poly(ethylene glycol) dimethyl ether (PEG500; $\mathrm{Mw}=\sim 500 \mathrm{Da}$ ), protease from Streptomyces griseus ("pronase"), and dichloromethane (DCM) were purchased from Sigma-Aldrich (St. Louis, USA). Horse spleen apoferritin (aFr) was purchased from Alfa Aesar (Ward Hill, USA). Immunoglobulin G (IgG) was purchased from LEE Biosolutions (St. Louis, USA). Dialysis tubing and vials were purchased from Spectrum Laboratories (Rancho Dominguez, USA). Sodium chloride, potassium chloride, sodium phosphate dibasic, potassium phosphate monobasic, mBlue, and Triton X-100 were purchased from Fisher Scientific (Suwanee, USA). All chemicals were of reagent grade unless otherwise stated. 
A 1510 Bransonic $^{\circledR}$ ultrasonic bath sonicator with a maximal energy of 70 watts was utilized for all sonication procedures (Bransonic Ultrasonics, Danbury, USA). Electroporation was performed using a Gene Pulser $^{\circledR}$ (Bio-Rad, Hercultes, CA, USA). Particle sizes were measured using Delsa ${ }^{\mathrm{TM}}$ Nano, a dynamic light scattering (DLS) instrument (Beckman Coulter, Indianapolis, USA). Mb and mBlue concentrations were determined by absorption spectroscopy using a Genesys ${ }^{\mathrm{TM}} 10 \mathrm{~S}$ UV-Vis spectrophotometer (Thermo Scientific, Suwanee, USA). The concentrations of all proteins in polymersome suspensions were further measured using a BCA Protein Assay Kit, utilizing UV-Vis spectrophotometry and by following the manufacturer's protocols (Pierce Biotechnology, Inc; Rockford, USA). Iron concentrations in polymersome-encapsulated Mb suspensions were determined using a Vista$\mathrm{PRO}^{\mathrm{TM}}$ CCD ICP-OES (Varian, USA). Oxygen equilibrium binding was studied using a Hemox ${ }^{\mathrm{TM}}$ Analyzer (TCS Scientific Corp, New Hope, USA).

\section{"Thin-film rehydration" method}

$10 \mathrm{mg}$ of $\mathrm{OB} 18$ polymer was dissolved in $200 \mu \mathrm{L}$ of DCM. The polymer solution was deposited on Teflon wafers $(15 \times 15 \mathrm{~mm})$ that were subsequently dried for $30 \mathrm{~min}$ at room temperature $(\mathrm{RT})$. The films were further kept under vacuum overnight at RT to ensure DCM evaporation. For mBlue encapsulation, polymer films were then hydrated with mBlue solution $(21 \mathrm{mg} / \mathrm{mL})$ in phosphate buffered saline (PBS; 10 $\mathrm{mM}, \mathrm{pH} 7.4$ ) for $24-48 \mathrm{~h}$ at 23,40 or $60{ }^{\circ} \mathrm{C}$. The samples were sonicated for $30 \mathrm{~min}$ at $\mathrm{RT}$, followed by (x10) freeze-thaw cycles using liquid nitrogen. The samples were dialyzed for $40 \mathrm{~h}$ at RT (MW cutoff = $100 \mathrm{kDa})$. For $\mathrm{Mb}$ encapsulation, polymer films were hydrated with $\mathrm{Mb}$ solution $(150 \mathrm{mg} / \mathrm{mL})$ in PBS $(10$ $\mathrm{mM}, \mathrm{pH} 7.4$ ) for $60 \mathrm{~h}$ at 23,40 , and $60{ }^{\circ} \mathrm{C}$. The samples were then sonicated for $30 \mathrm{~min}$ at $\mathrm{RT}$ followed by dialysis for $40 \mathrm{~h}$ at $4{ }^{\circ} \mathrm{C}(\mathrm{MW}$ cutoff $=1000 \mathrm{kDa})$. The dialysis buffer was exchanged with 1 Liter of fresh buffer every after 7-8 h; free mBlue or Mb solutions were also subject to dialysis and served as controls to verify their full removal in the dialysate under these conditions. Quantification of mBlue and Mb encapsulation in polymersomes was determined vida infra (see "Quantification of mBlue/Mb"). 


\section{"Direct hydration" method}

The "direct hydration" method was adopted from O'Neil et al. with minor modification (22). In brief, the protocol consists of 4 steps: 1) addition of $10 \mathrm{mg}$ of OB18 to $10 \mathrm{mg}$ of PEG500 followed by heating a 1.5 $\mathrm{mL}$ centrifuge tube for $20 \mathrm{~min}$ at $95{ }^{\circ} \mathrm{C}$; 2) mixing by vortexing and cooling to RT followed by the addition of $10 \mu \mathrm{L}$ of mBlue solution $(21 \mathrm{mg} / \mathrm{mL})$ or Mb solution $(150 \mathrm{mg} / \mathrm{mL})$ in PBS (10 mM, pH 7.4); 3) diluting with 20,70, and $900 \mu \mathrm{L}$ of PBS with mixing after each step (via vortexing); and 4) dialysis for $30 \mathrm{~h}$ at $\mathrm{RT}$ or at $4{ }^{\circ} \mathrm{C}(\mathrm{MW}$ cutoff $=1000 \mathrm{kDa})$ to remove unencapsulated mBlue or $\mathrm{Mb}$, respectively. The dialysis buffer was exchanged with 1 Liter of fresh buffer every after 7-8 h. Quantification of mBlue and $\mathrm{Mb}$ encapsulation in polymersomes suspensions was determined vida infra. As control experiments, free mBlue and Mb suspensions were also subject to similar dialysis conditions; UV-Vis spectroscopy of both the dialysate and retained solution suspensions at the completion of the dialysis experiment demonstrated no retention of unencapsulated agent by the dialysis membrane.

\section{Quantification of mBlue/Mb}

The amounts of mBlue or $\mathrm{Mb}$ that were encapsulated in dialyzed polymersome suspensions were determined by measuring the solution absorbance at $665 \mathrm{~nm}$ (mBlue) or at $410 \mathrm{~nm}(\mathrm{Mb})$, using a UV-Vis spectrophotometer. In brief, calibration curves for mBlue and $\mathrm{Mb}$ were developed using serial dilutions of known concentrations. Before UV-vis measurements, polymersome-encapsulated mBlue or Mb samples were diluted with a 10 -fold excess volume of THF or $1 \%$ triton, respectively. This step was necessary to destroy the vesicles and release the encapsulated mBlue or $\mathrm{Mb}$ agent, thereby reducing light scattering during UV-Vis measurements that would otherwise ensue due to intact particles. The UV-vis spectra were also baseline corrected to obtain the peak absorbance of mBlue or $\mathrm{Mb}$ in solution. The samples concentration of mBlue or $\mathrm{Mb}$ from the dialysis controls were similarly subtracted from the concentration of the mBlue or $\mathrm{Mb}$ in the destroyed polymersome samples to obtain the absolute concentration each agent in the original polymersome suspension. To measure the iron content in PEM suspensions (as a 
corroboration of $\mathrm{Mb}$ concentration in that sample), 5-10\% (v/v) of Triton X-100 was added; the mixture was digested by heating in aqua regia for $3 \mathrm{~h}$ at $98{ }^{\circ} \mathrm{C}$ and the sample was subsequently diluted with deionized water. ICP-OES measurements were then conducted and the iron content in the experimental samples was determined by comparison to the standard calibration curve. For each experimental sample, the concentrations of $\mathrm{Mb}$ (as calculated by UV-Vis) were compared to those obtained via ICP-OES and via the BCA assay, which was also conducted by utilizing UV-Vis spectrophotometry and by following the manufacturer's protocols (Pierce Biotechnology, Inc; Rockford, USA). Loading of aqueous encapsulants in polymersomes was quantified and expressed as the final weight percentages of encapsulant-to-polymer that comprised the vesicles in suspension (e.g. w/w\% Mb/polymer).

\section{Quantification of metMb}

The amount of metmyoglobin (metMb, i.e. oxidized $\mathrm{Mb}$ with an $\mathrm{Fe}(\mathrm{III})$-heme group) in polymersome suspensions was quantified using a modified UV-Vis absorption protocol that was previously established for the measurement of cyanomethemoglobin (38-43). In brief, the absorbance of Mb was measured at $630 \mathrm{~nm}\left(L_{1}\right)$ against a blank reference (deionized water). One drop of $\mathrm{KCN}$ solution (1 part $10 \% \mathrm{KCN}$ and 1 part $50 \mathrm{mM}$ phosphate, $\mathrm{pH}$ 7.6) was added and mixed with the treated $\mathrm{Mb}$ samples. This reaction step was necessary to convert metMb to cyanometmyoglobin (cyanoMb), which does not absorb at $630 \mathrm{~nm}$. After $2 \mathrm{~min}$, the absorbance was measured at $630 \mathrm{~nm}\left(L_{2}\right)$; the absorbance of deionized water served as the blank reference. The concentration of metMb was determined using Equation 1:

$[\mathrm{metMb}](\mathrm{mM})=\frac{L_{1}-L_{2}}{1 \times E} \times D_{1}$

where $E=3.7(\mathrm{~cm} \times \mathrm{mM})^{-1}$ and is the extinction coefficient of metMb at $630 \mathrm{~nm} ; D_{1}$ is the dilution factor in this experiment (cuvette length $=1 \mathrm{~cm}$ as denoted in the equation).

To determine the concentration of $\mathrm{Mb}$, one drop of $20 \% \mathrm{~K}_{3}\left(\mathrm{Fe}(\mathrm{CN})_{6}\right)$ was added and mixed with the treated $\mathrm{Mb}$ sample. The solution was allowed to react for $2 \mathrm{~min}$ and an additional drop of $10 \% \mathrm{KCN}$ was 
added and mixed. The absorbance of the sample was then measured at $540 \mathrm{~nm}$ (L3). The concentration of total $\mathrm{Mb}$ was determined using Equation 2:

$[$ total $\mathrm{Mb}](\mathrm{mM})=\frac{L_{3}}{1 \times E} \times D_{2}$

where $E=11.3(\mathrm{~cm} \times \mathrm{mM})^{-1}$ and is the extinction coefficient for cyanometMb at $540 \mathrm{~nm} ; D_{2}$ is the dilution factor (cuvette length $=1 \mathrm{~cm}$ as denoted in the equation).

The percentage of metMb in the original solution was determined using Equation 3:

$[\operatorname{metMb}](\%)=\frac{[\text { metMb }]}{[\text { metMb }]+[\text { total Mb }]} \times 100$

\section{Structural characterization of polymersomes}

Polymersome suspensions were diluted in PBS solution and their hydrodynamic diameters were measured by DLS using a standard $1.5 \mathrm{~mL}$ semi-micro Plastibrand polystyrene cuvette (VWR, Atlanta, USA). The morphologies of blank polymersomes and PEM were visualized by cryo-TEM (JEOL 2100F, USA). In brief, polymersome samples were suspended in a microperforated grid, rapidly vitrified using liquid ethane $\left(-183{ }^{\circ} \mathrm{C}\right)$, and loaded onto a cryogenic sample holder for cryo-TEM imaging at $200 \mathrm{kV}$.

\section{Optimization of various steps in the direct hydration protocol}

Modification of each of the 4 steps in the original direction hydration protocol were conducted following protocols summarized below as well as in Table II.

Modification of Step 1: Effects of blending of polymer and PEG using an organic solvent vs. heat

Following the "direct hydration" protocol (vide supra), $10 \mathrm{mg}$ of OB18 and $10 \mathrm{mg}$ of PEG500 were blended either by: A) mixing by dissolution in DCM (50 $\mu \mathrm{L})$, or B) heating to $95^{\circ} \mathrm{C}$ for $1 \mathrm{~h}$ followed by cooling to room temperature. Samples that were blended by dissolution in DCM were further subject to drying under vacuum at RT (overnight) to ensure removal of all organic solvent prior to addition of 
aqueous protein solutions. In the case of heating, the samples were subject to $95{ }^{\circ} \mathrm{C}$ for $1 \mathrm{~h}$ (instead of only $20 \mathrm{~min}$ as utilized in the original "direct hydration" protocol) to further ensure maximal polymer mixing prior to cooling. In all cases, Mb concentrations in the final suspensions were determined by UVVis, ICP-OES and compared.

Modification of Step 2: Effects of Mb oxidation state (i.e. utilizing metMb vs. oxymyoglobin)

The "direct hydration protocol" (vide supra) was modified to expose the initial mixture of polymer and PEG500 to $1 \mathrm{~h}$ (instead of $20 \mathrm{~min}$ ) of heating at $95{ }^{\circ} \mathrm{C}$. The effect of the oxidation state of iron in the heme group of $\mathrm{Mb}$ on the efficiency of polymersome encapsulation was studied by using metMb vs. oxymyoglobin (oxyMb; i.e. $\mathrm{Fe}(\mathrm{II}) \mathrm{Mb}$ ) for polymersome encapsulation. MetMb solution was first prepared by dissolving lyophilized $\mathrm{Mb}$ in PBS; the same solution was treated with 1 wt $\% \mathrm{Na}_{2} \mathrm{~S}_{2} \mathrm{O}_{4}$ to obtain the reduced $\mathrm{Mb}$ form (oxyMb). Mb concentrations, weight percentages of Mb-to-polymer, and the final efficiencies of polymersome encapsulation of $\mathrm{Mb}$, using either metMb vs. oxyMb in the protocol, were measured by UV-Vis, ICP-OES and compared.

\section{Modification of Step 2: Effects of sonication and temperature on Mb oxidation}

Lyophilized $\mathrm{Mb}$ was dissolved in PBS (at $150 \mathrm{mg} / \mathrm{mL}$ ) and reduced with $\mathrm{Na}_{2} \mathrm{~S}_{2} \mathrm{O}_{4}$ to obtain an oxyMb solution that was further subjected to various environmental conditions, including heating at $40{ }^{\circ} \mathrm{C}$ or at $50{ }^{\circ} \mathrm{C}$ (with or without sonication) for $2-5 \mathrm{~h}$. The extent of Mb oxidation was determined by measuring the percentages of metMb in the total polymersome-encapsulated (oxy)Mb suspensions, using the cyanomethemoglobin method (vide supra).

\section{Modification of Step 3: Effects of sonication after each dilution step}

Following the "direct hydration protocol" (vide supra), upon addition of PEG500 to OB18 polymer, the sample was heated, mixed by vortexing, cooled to RT, and $10 \mu \mathrm{L}$ of $\mathrm{Mb}$ solution $(150 \mathrm{mg} / \mathrm{mL})$ in PBS (10 mM, pH 7.4) were added. The sample was then further combined with 10, 20, 50, and, finally, $100 \mu \mathrm{L}$ 
of PBS, followed by sonication for either: A) $0 \mathrm{~min}$, B) $15 \mathrm{~min}$, C) $30 \mathrm{~min}$, D) $45 \mathrm{~min}$, or E) $60 \mathrm{~min}$ after each dilution step. All samples were then dialyzed for $40 \mathrm{~h}$ at $4{ }^{\circ} \mathrm{C}(\mathrm{MW}$ cutoff $=1000 \mathrm{kDa})$. The final $\mathrm{Mb}$ concentrations, weight percentages of Mb-to-polymer, and the efficiencies of polymersome encapsulation of $\mathrm{Mb}$ were measured by UV-Vis, ICP-OES and compared.

Modification of Step 4: Effects of proteolysis to distinguish non-specifically bound vs. encapsulated protein in the final polymersome suspensions

PEM suspensions were generated by the "direct hydration" method (vide supra), using OB18 polymer and oxyMb solution $(150 \mathrm{mg} / \mathrm{mL})$ with subsequent dialysis at $4{ }^{\circ} \mathrm{C}$ for at least $40 \mathrm{~h}(\mathrm{MW}$ cutoff $=1000$ $\mathrm{kDa}$ ). The samples were then treated with $0.4 \mathrm{wt} \%$ pronase solution for $1,2,3,6,12,18$, or $24 \mathrm{~h}$ at $\mathrm{RT}$ and again dialyzed overnight at $4{ }^{\circ} \mathrm{C}$. Free oxyMb solutions were also subjected to similar pronase treatment in order to serve as a positive control (for the rate and extent of proteolysis). Mb encapsulation in polymersomes (before and after proteolysis) was measured by UV-Vis, ICP-OES and compared.

Improvement of Mb encapsulation efficiency (\%Mb EE)

Following the "direct hydration" protocol, $10 \mathrm{mg}$ polymer and $10 \mathrm{mg}$ of PEG500 were initially heated in $1.5 \mathrm{~mL}$ microcentrifuge tubes for $1 \mathrm{~h}$ at $95{ }^{\circ} \mathrm{C}$ and subsequently cooled to RT. Different volumes of: A) pure PBS, or B) 5 different $\mathrm{Mb}$ solutions (varying in concentration from 8 to $150 \mathrm{mg} / \mathrm{mL}$ oxyMb in PBS) were then combined with this mixture in 5 addition steps: i.e. $10,10,20,50$, and, finally, $100 \mu \mathrm{L}$ of solution were added to the polymer mixture. When introducing additional amounts of $\mathrm{Mb}$ to the polymer mixture, the final (v/v) ratio of Mb to PBS (i.e. "Mb:PBS") used in each of the 5 addition steps were 10:180 (i.e. $8 \mathrm{mg} / \mathrm{mL} \mathrm{Mb),} \mathrm{20:170} \mathrm{(i.e.} 15 \mathrm{mg} / \mathrm{mL} \mathrm{Mb),} \mathrm{40:150} \mathrm{(i.e.} 31 \mathrm{mg} / \mathrm{mL} \mathrm{Mb),} \mathrm{90:100} \mathrm{(i.e.} 71$ $\mathrm{mg} / \mathrm{mL} \mathrm{Mb}$ ), and 190:0 (i.e. $150 \mathrm{mg} / \mathrm{mL} \mathrm{Mb}$ ). The samples were then proteolyzed using $0.4 \mathrm{wt} \%$ pronase and again dialyzed overnight at $4{ }^{\circ} \mathrm{C}(\mathrm{MW}$ cutoff $=1000 \mathrm{kDa})$. Mb encapsulation was measured using UV-Vis spectrophotometry. Mb encapsulation efficiencies were calculated using Equation 4: 
Mb Encapsulation Efficiency $=\left[1-\frac{v_{1} c_{1}-v_{2} c_{2}}{v_{1} c_{1}}\right] \times 100$

Where $v_{1}=$ Initial volume of the unencapsulated $\mathrm{Mb}(\mathrm{mL}) ; \mathrm{c}_{1}=$ Initial concentration of unencapsulated $\mathrm{Mb}(\mathrm{mg} / \mathrm{mL}) ; v_{2}=$ volume of polymersome-encapsulated Mb obtained after dialysis and proteolysis $(\mathrm{mL})$; $\mathrm{c}_{2}=$ concentration of encapsulated $\mathrm{Mb}$ obtained after dialysis and proteolysis $(\mathrm{mg} / \mathrm{mL})$.

\section{Development of the "progressive saturation" technique}

In combining the various experimental conditions that yielded the most favorable results in each of the comparative experiments (vide supra), a "progressive saturation" technique was developed that optimized the generation of polymersome-encapsulated protein suspensions. In brief, $10 \mathrm{mg}$ of polymer and $10 \mathrm{mg}$ of PEG500 were heated to $95{ }^{\circ} \mathrm{C}$ for $1 \mathrm{~h}$. The mixture was then centrifuged and cooled to RT. Lyophilized $\mathrm{Mb}$ protein was dissolved in PBS, reduced with $\mathrm{Na}_{2} \mathrm{~S}_{2} \mathrm{O}_{4}(1 \mathrm{wt} \%)$ to generate an oxyMb solution (at 150 $\mathrm{mg} / \mathrm{mL}$ in PBS), and used for stepwise addition to the polymer mixture: 10, 10, 20, 50 and $100 \mu \mathrm{L}$ of oxyMb solution were introduced, followed by thorough mixing and sonication for $30 \mathrm{~min}$ at RT after each step. The samples were then sonicated for an additional $30 \mathrm{~min}$ at RT followed by dialysis at $4{ }^{\circ} \mathrm{C}$ for at least $40 \mathrm{~h}(\mathrm{MW}$ cutoff $=1000 \mathrm{kDa})$. The dialysate was exchanged with 1 Liter of fresh buffer every after 8-10 $\mathrm{h}$ and UV-Vis measurements of the dialysis control solution (e.g. free Mb solution subject to identical dialysis conditions) verified that all free protein was successfully removed. Surface-associated protein was further eliminated by proteolysis via treatment with $0.4 \mathrm{wt} \%$ pronase solution followed by a second overnight dialysis at $4{ }^{\circ} \mathrm{C}$ (MW cutoff $=1000 \mathrm{kDa}$ ). Mb encapsulation (before and after proteolysis) in polymersome suspensions was determined via UV-vis, ICP-OES and compared.

\section{Stability of polymersome-encapsulated protein suspensions}

PEM suspensions were prepared from OB18 polymer and oxyMb using the optimized "progressive saturation" technique (vide supra). The samples were stored at 4,23 , and $37{ }^{\circ} \mathrm{C}$ for 2 weeks. At predetermined time points, Mb concentrations were quantified using UV-Vis spectroscopy (vide supra); 
weights of polymer were measured after lyophilization; and, particle sizes were determined by DLS for PEM suspensions under each condition.

\section{Equilibrium binding of oxygen in polymersome-encapsulated Mb suspensions}

The equilibrium binding and dissociation curves for oxygen in suspensions of free $\mathrm{Mb}$ and PEM were obtained at $37{ }^{\circ} \mathrm{C}$ using a $\mathrm{Hemox}^{\mathrm{TM}}$ - Analyzer. Samples were allowed to saturate to a $\mathrm{pO}_{2}$ of $147 \mathrm{mmHg}$ (using compressed air) and then deoxygenated (using a compressed nitrogen stream). The absorbance of oxygenated and deoxygenated free $\mathrm{Mb}$ and $\mathrm{PEM}$ suspensions were recorded as a function of $\mathrm{pO}_{2}$ via dual wavelength spectroscopy. Oxygen equilibrium curves were fit to a four-parameter $\left(\mathrm{A}_{0}, \mathrm{~A}_{\infty}, \mathrm{P}_{50}, \mathrm{n}\right) \mathrm{Hill}$ model (Equation 5). In this model, $\mathrm{A}_{0}$ and $\mathrm{A}_{\infty}$ represent the absorbance at $0 \mathrm{mmHg}$ and at $147 \mathrm{mmHg}$, respectively. The $\mathrm{pO}_{2}$ represents the partial pressure of oxygen; $\mathrm{P}_{50}$ represents the partial pressure where the sample is $50 \%$ saturated with $\mathrm{O}_{2}$; and, $n$ represents the cooperativity coefficient for the sample.

$$
Y=\frac{A b s-A_{0}}{A_{\infty}-A_{0}}=\frac{p O_{2}^{n}}{p O_{2}^{n}+P_{50}^{n}}
$$

\section{Polymersome encapsulation of different proteins using the "progressive saturation" technique}

The generalizability of the "progressive saturation" technique was tested using proteins of varying sizes: i.e. $\mathrm{Mb}(17 \mathrm{kDa})$, hemoglobin $(\mathrm{Hb} ; 64 \mathrm{kDa})$, bovine serum albumin (BSA; $66 \mathrm{kDa})$, immunoglobulin $\mathrm{G}$ (IgG: $150 \mathrm{kDa})$, catalase $(250 \mathrm{kDa})$, fibrinogen $(340 \mathrm{kDa})$, and apoferritin (450 kDa). Each protein was dissolved in PBS (10 mM, pH 7.4) at its maximal solubility, corresponding to final suspension concentrations of $150,150,40,20,50,50$, and $25 \mathrm{mg} / \mathrm{mL}$, respectively. The "progressive saturation" protocol was followed to encapsulate these proteins in OB29 polymersomes. Free proteins were separated by dialysis for at least $40 \mathrm{~h}$ at $4{ }^{\circ} \mathrm{C}(\mathrm{MW}$ cutoff $=1000 \mathrm{kDa}$ ). Surface-associated protein was removed by proteolysis via treatment with $0.4 \mathrm{wt} \%$ pronase solution followed by overnight dialysis at $4{ }^{\circ} \mathrm{C}(\mathrm{MW}$ cutoff $=1000 \mathrm{kDa}$ ). Protein encapsulation (before and after proteolysis) in polymersome suspensions was quantified via the BCA assay, utilizing UV-Vis spectrophotometry and by following the manufacturer's 
protocols (Pierce Biotechnology, Inc; Rockford, USA). The final concentrations of protein were divided by those of polymer and expressed as the final weight ratios of protein-to-polymer that comprised the polymersomes in suspension (i.e. w/w\% Mb/polymer).

\section{Statistical analysis}

Data are presented as the mean \pm the standard deviation of the mean (SD). A minimum of three experimental replicates was used for each condition. One-way analysis of variance (ANOVA) was conducted using GraphPad software (San Diago, USA). A $p$ value of $<0.05$ was considered statistically significant.

\section{RESULTS}

\section{Encapsulation of mBlue and $\mathrm{Mb}$ in polymersome suspensions using conventional methods}

In order to establish a baseline for comparisons of small molecule and protein encapsulation in polymersome suspensions, the final concentrations, weight percentages (i.e. weight of encapsulated agent compared to the weight of the polymer that comprises the nanoparticle), and the efficiencies of encapsulation for the small molecule mBlue were first determined with OB18-based polymersomes. Using the "thin-film rehydration" method, no significant differences in mBlue encapsulation were observed in polymersomes formed at 40 vs. $60{ }^{\circ} \mathrm{C}$ (e.g. final polymersome composition consisted of 4.1 vs. $5.0 \mathrm{w} / \mathrm{w} \% \mathrm{mBlue} /$ polymer, respectively; Fig. 1A). When thin-film rehydration was attempted at $23{ }^{\circ} \mathrm{C}$ (room temperature), the encapsulation of mBlue was found to be negligible (results not shown), possibly due to the observation that the polymer films did not swell after 48-72 $\mathrm{h}$ of hydration; PEO-b-PBD-based polymersomes require the input of energy for vesicle formation, which is usually supported by using elevated temperatures (e.g. $\left.>45{ }^{\circ} \mathrm{C}\right)(8,44)$. To improve the efficiency of encapsulation at lower temperatures, which would be necessary when employing labile proteins, encapsulation of mBlue was 
also studied by the "direct hydration" method; the final weight ratio of mBlue-to-polymer in these polymersomes was, however, again found to be very low $(\sim 1.2 \mathrm{w} / \mathrm{w} \% \mathrm{mBlue} /$ polymer; Fig $1 \mathbf{1 B})$.

We next sought to compare the results obtained for mBlue encapsulation to those that could be achieved for $\mathrm{Mb}$ using the same polymersome formation techniques. Polymersome-encapsulated $\mathrm{Mb}$ (PEM) suspensions formed at $23{ }^{\circ} \mathrm{C}$ by "thin-film rehydration" were initially found to be comprised of $\sim 2.7$ w/w\% Mb/polymer. After the addition of a proteolysis step to remove any surface-associated Mb (i.e. free protein that was nonspecifically bound), the final composition of the polymersomes was found to be only $\sim 0.5 \mathrm{w} / \mathrm{w} \% \mathrm{Mb} /$ polymer, indicating that only very small amounts of protein were being encapsulated within polymersomes via this method (Fig 1C). In order to improve the concentrations and the final weight percentages of $\mathrm{Mb}$ in $\mathrm{PEM}$ suspensions, polymersome generation at higher temperatures was again attempted (e.g. utilizing "thin-film rehydration" at 40 and $60{ }^{\circ} \mathrm{C}$ ); these experiments, however, only resulted in protein denaturation and aggregation (results not shown). In contrast, PEM suspensions prepared by "direct hydration" at $23{ }^{\circ} \mathrm{C}$ displayed good colloidal properties and the characteristic absorption spectra of intact $\mathrm{Mb}$; the final loading ratio of Mb-to-polymer in these PEM suspensions, however, was again very low (i.e. $\sim 0.3$ and $0.1 \mathrm{w} / \mathrm{w} \% \mathrm{Mb} /$ polymer before and after proteolysis, respectively; Fig 1D). Thus, while "thin-film rehydration" and "direct hydration" may be used to reproducibly encapsulate mBlue at reasonable efficiencies, their utility for Mb encapsulation was found to be uniformly poor.

\section{Optimization of the "direct hydration" protocol to improve protein encapsulation}

In order to develop an improved method for the generation of polymersome-encapsulated protein suspensions, the contributions of each of the various steps in the "direct hydration" protocol on the final concentrations, weight percentages, and encapsulation efficiencies of $\mathrm{Mb}$ in OB18-based polymersomes were systematically evaluated (Table II). We sought to combine features of both the "direct hydration" 
and "thin-film rehydration" techniques in order to improve polymersome encapsulation of functional protein. As such, changes were implemented iteratively in order to optimize experimental conditions.

Step 1: Effects of blending technique (i.e. dissolving polymer in organic solvent vs. adding heat)

Improving polymer dissolution is critical to efficient encapsulation of protein. As such, we sought to first compare the effects of utilizing an organic solvent versus adding heat in order to blend OB18 with PEG500 homopolymer in the first step of the "direct hydration" protocol; we subsequently compared both strategies with respect to the final yield of polymersomes and, ultimately, to the concentrations and efficiencies of protein encapsulation that could be obtained by each method. If the two polymers were first mixed by dissolution in DCM (followed by polymersome formation after organic solvent evaporation), the final weight ratio of Mb-to-polymer in PEM suspensions was $\sim 2 \mathrm{w} / \mathrm{w} \% \mathrm{Mb} /$ polymer. In comparison, initial heating of dry OB18 and PEG500 to $95{ }^{\circ} \mathrm{C}$ for $1 \mathrm{~h}$ improved mixing and promoted more efficient polymersome generation, yielding a significantly higher final weight ratio of Mb-topolymer in the PEM suspensions ( $\sim 5$ w/w\% Mb/polymer; Fig 2A), corresponding to a greater amount of encapsulated protein.

Step 2: Effects of Mb oxidation state (utilizing metMb vs. oxyMb for polymersome encapsulation)

In addition to improving polymeric blending, $\mathrm{Mb}$ encapsulation in polymersomes was found to be further augmented when the starting Mb stock solution was first reduced with sodium dithionite to convert all metMb to the oxyMb form. OxyMb contains a central heme group with iron in the ferrous state (i.e. $\mathrm{Fe}(\mathrm{II})$ ), which improves the solubility of the protein when compared to its metMb form that contains $\mathrm{Fe}(\mathrm{III})$. This oxyMb solution was further desalted via dialysis prior to utilization in the initial addition step of the "direct hydration" protocol, which was found to be necessary to increase the loading of Mb in PEM suspensions (i.e. the final weight ratio of Mb-to-polymer). When oxyMb was used in the initial protocol step, PEM suspensions comprised of $\sim 6 \mathrm{w} / \mathrm{w} \% \mathrm{Mb} /$ polymer were formed, which was a 
statistically significant improvement over the $4 \mathrm{w} / \mathrm{w} \% \mathrm{Mb}$ /polymer that could be obtained if metMb was utilized instead (Fig 2B).

Step 2: Effects of sonication and temperature on Mb oxidation

More than $40 \%$ of the oxyMb that was used in the initial step for polymersome encapsulation was found to be reoxidized to metMb within $2 \mathrm{~h}$ at $50{ }^{\circ} \mathrm{C}$; by contrast, only $\sim 15 \%$ metMb was generated from the initial oxyMb solution if lower temperatures were employed for polymersome formation (e.g. heating for $2 \mathrm{~h}$ at $40{ }^{\circ} \mathrm{C}$ ). The rate of $\mathrm{Mb}$ oxidation at $50{ }^{\circ} \mathrm{C}$ was also significantly higher than that observed at $40{ }^{\circ} \mathrm{C}$, regardless of the addition of sonication or the power that was utilized (Fig 2C). As such, it was determined that sonication had no effect on Mb oxidation; and, it was, thus, preferentially employed to both promote polymer mixing and to provide interfacial energy to augment polymersome formation.

Step 3: Effects of sonication on improving the encapsulation of $\mathrm{Mb}$ in polymersomes

Despite improvements in polymer blending that could be afforded by heating the polymer and PEG500 solution in the first step of the "direct hydration protocol", as well as increases in the yield of myoglobin in the final vesicles suspensions afforded by utilizing oxyMb for polymersome encapsulation, the final weight ratios of Mb-to-polymer that were reproducibly obtained in PEM suspensions after pronase treatment were found to again be very low $(\sim 0.2 \mathrm{w} / \mathrm{w} \% \mathrm{Mb} /$ polymer $)$, indicating that most of the Mb was only surface associated as opposed to encapsulated within the vesicle suspensions. The encapsulation efficiency, however, could be increased by $>30 \mathrm{x}$ if the samples were sonicated for $30 \mathrm{~min}$ at $\mathrm{RT}$ after each dilution step (i.e. sonicating after introducing additional volumes of aqueous solution to dilute the concentrations of polymer in suspension). As seen from the results depicted in Fig 2D, the relative amounts of $\mathrm{Mb}$ in PEM suspensions could be increased to $\sim 5.5 \mathrm{w} / \mathrm{w} \% \mathrm{Mb} /$ polymer, supporting the addition of this sonication step to the original "direct hydration" protocol. 
Step 4: Effects of proteolysis on differentiating surface-associated vs. encapsulated Mb

Upon formation, PEM suspensions were treated with $0.4 \%$ pronase solution for up to $24 \mathrm{~h}$ at RT in order to examine the duration of time required for the complete digestion of any surface-associated (i.e. nonspecifically bound) Mb. It was observed that all free protein in solution, which was utilized as a positive control for proteolysis, and all surface-associated Mb in PEM suspensions were digested in $2 \mathrm{~h}$; neither increasing pronase exposure time nor concentration further augmented $\mathrm{Mb}$ loss. These results would indicate that only encapsulated $\mathrm{Mb}$ was thereafter retained (Fig 2E).

\section{Optimization of Mb encapsulation efficiency}

Five sets of experiments were done with various Mb-to-PBS volume ratios (Mb:PBS) in order to establish the optimal $\mathrm{Mb}$ concentration to use in each subsequent addition step in our modification of the original "direct hydration" protocol. Notably, when Mb:PBS increased, the final w/w\% Mb/polymer in the PEM suspensions also increased; but, the Mb encapsulation efficiency (\% Mb EE) decreased as a result. In other words, the final Mb-to-polymer mass ratio was maximized when all addition steps were conducted using a maximally concentrated $\mathrm{Mb}$ solution (i.e. $\mathrm{Mb}: \mathrm{PBS}=190: 0$, corresponding to $150 \mathrm{mg} / \mathrm{mL}$ oxyMb) (Fig 2F). \% Mb EE (as defined in Materials and Methods), however, was largest when Mb:PBS was minimal (i.e. 10:180). As the amount of protein in the final polymersome suspension is ultimately the metric that must be optimized for therapeutic administration (in order to minimize the amount of associated carrier polymer that is introduced to a subject), it was determined that a pure $\mathrm{Mb}$ solution (i.e. $150 \mathrm{mg}$ oxyMb/mL) would be used for each addition step in the ultimate encapsulation protocol, maximizing the final loading of myoglobin (i.e. w/w\% Mb/polymer) in PEM suspensions.

\section{Maximizing protein encapsulation through "progressive saturation"}

By incorporating each of the aforementioned steps, an optimized "progressive saturation" technique was established that improved upon the results of the original "direct hydration" method (Scheme 1D). Following the "progressive saturation" protocol, the final content of $\mathrm{Mb}$ in OB-18-based PEM 
suspensions was found to be 6.1 and $3.2 \mathrm{w} / \mathrm{w} \% \mathrm{Mb} /$ polymer before and after proteolysis, respectively. Quantification of the iron content (and hence the numbers of intact heme groups in each of the polymersome suspensions) by ICP-OES corroborated UV-Vis measurements of protein concentration; the final loading percentages of $\mathrm{Mb}$ in the polymersomes were found to be 7.9 and $5.1 \mathrm{w} / \mathrm{w} \% \mathrm{Mb} /$ polymer before and after proteolysis, respectively (Table III). Notably, the percentage of metMb (with respect to the total $\mathrm{Mb}$ content in these suspensions) was determined by UV-Vis spectrophotometry and found to be $\sim 8$ and $6 \%$ in non-proteolyzed (PEM-SE) and proteolyzed (PEM-E) samples, respectively (Table III).

\section{Polymersome encapsulation using block copolymers and proteins of varying molecular weight}

The "progressive saturation" technique was also utilized to encapsulate Mb in a second PEO-b-PBDbased polymersome system comprised of the OB29 diblock copolymer. When compared to OB18, OB29 has a smaller molecular weight $(\mathrm{Mw}=3800 \mathrm{~g} / \mathrm{mol}$ vs. $10400 \mathrm{~g} / \mathrm{mol})$ and generates polymersomes with a shorter PEG brush border (1.3 vs. $3.9 \mathrm{kDa})$, thinner bilayer membrane ( $9.6 \mathrm{~nm}$ vs. $14.8 \mathrm{~nm})$, and smaller average hydrodynamic diameter (130 vs. $200 \mathrm{~nm}$ ) (Table I) $(36,37)$. When compared to the initial experiments with OB18, similar encapsulation results were obtained with $\mathrm{Mb}$ in OB29-based polymersomes (Table IV). The generalizability of the "progressive saturation" technique was further established when analogous results were obtained with several larger proteins, including hemoglobin (Hb; $64 \mathrm{kDa}$ ), bovine serum albumin (BSA; $66 \mathrm{kDa})$, immunoglobulin $\mathrm{G}$ (IgG: $150 \mathrm{kDa})$, catalase (250 kDa), fibrinogen (340 kDa), and apoferritin (450 kDa) (Table IV).

\section{Characterization of the final PEM suspensions}

The size distributions of the final OB18- and OB29-based PEM suspensions were measured by both DLS

(Fig. 3A) and by cryo-TEM (Fig. 3B and Fig. 3C). These results confirmed a mean particle diameter of approximately 200 and $130 \mathrm{~nm}$ for OB18 vs. OB29-based polymersomes, respectively. The stability of the OB18-based PEM suspensions were further examined over 2 weeks and at three different temperatures (i.e. 4,23 , and $37^{\circ} \mathrm{C}$ ); the particles demonstrated no aggregation as evidence by their 
consistent particle numbers and stable size distributions in suspension (Fig. 3D). The extent of $\mathrm{Mb}$ encapsulation in these PEM suspensions was also found to be unaffected after two weeks of exposure to these three different temperatures (Fig. 3E). Finally, the functional status of encapsulated Mb in the PEM suspensions (i.e. retention of Mb's ability to bind and release oxygen) was verified by dual wavelength spectroscopy (Fig. 3F). The oxygen equilibrium curve of PEM after proteolysis (PEM-E) was similar to that of free Mb but demonstrated a slightly hyperbolic shape at lower oxygen tensions, indicating the encapsulation of functional protein within polymersomes but with subtle changes in oxygen binding and release; the $\mathrm{P}_{50}$ (i.e. the partial pressure that corresponds to $50 \%$ saturation with $\mathrm{O}_{2}$ ) and $\mathrm{n}$ (the cooperativity coefficient) for PEM-E were also larger than that of free Mb (Table V). The oxygen equilibrium curve and the values of $\mathrm{P}_{50}$ and $\mathrm{n}$ for PEM before proteolysis (PEM-SE) were intermediate between those of free $\mathrm{Mb}$ and PEM-E, supporting the incorporation of both surface-associated and encapsulated $\mathrm{Mb}$ in these vesicle suspensions.

\section{DISCUSSION}

While lipid-based vesicles (i.e. liposomes) have been extensively utilized in biomedical research, examples of their widespread clinical adoption are few. These translational shortcomings may be attributable to material limitations inherent to phospholipid-based drug delivery vehicles, including compromised suspension stability, premature drug release, and limited product shelf-life. In contrast, polymersomes are formed from higher molecular weight amphiphilic block copolymers that impart a broad and tunable range of carrier properties. To date, however, a generalized method for the efficient and reproducible encapsulation of functional proteins in neutrally charged, fully PEGylated, and nanoscale polymer vesicles has not been established. While adoption of various liposome encapsulation techniques has enabled facile incorporation of small molecules within polymersomes, these methods cannot directly be applied for scalable encapsulation of functional proteins. Often, there is a trade-off in the maximal 
concentration of aqueous protein that may be encapsulated (i.e. $\mathrm{mg}$ protein/mL solution), the final loading ratio of protein-to-polymer that comprises the polymersome structure (i.e. w/w\% protein/polymer), and/or the protein encapsulation efficiency (i.e. the percentage of the initial protein suspension that is retained). Further, the value of each of these parameters often varies upon experimental run and is highly dependent on the nature of the protein, the exact block copolymer formulation, and the encapsulation method that is utilized (Table VI). Here, we have performed a comparative and quantitative study of several conventional liposome encapsulation techniques in order to generate an optimized and reproducible method to improve the encapsulation of functional proteins in nanoscale polymer vesicles.

PEO-b-PBD copolymers were used to form polymersomes that possessed fully PEGylated surfaces, that were uncharged, and that were nondegradable; thus, they were an ideal system for ensuring vesicle integrity and minimizing unwanted protein interactions or modifications. Two different molecular weight PEO-b-PBD polymers (i.e. OB18 and OB29) were further employed to determine the generalizability of the results as they pertain to polymersomes of different PEG lengths, membrane core thicknesses, and minimal sizes. Methylene blue (mBlue; $\mathrm{Mw}=319.85 \mathrm{~g} / \mathrm{mol}$ ) was first used as a model small molecule in order to establish the baseline encapsulation parameters (i.e. aqueous suspension concentrations, final weight percentages, and encapsulation efficiencies) that could be obtained by each method. mBlue is highly stable in aqueous suspension and has a strong near-infrared absorbance that enables ready spectrophotometric detection; it was thus employed to confirm the fidelity of the results in reference to previously published studies on the encapsulation of other organic small molecules. Mb was used as a model protein for polymersome encapsulation as it possesses a size ( $\mathrm{Mw}=17,600 \mathrm{Da}$ ) and thermal stability (denaturation above $60{ }^{\circ} \mathrm{C}$ ) that is comparable to other small proteins with therapeutic potential; $\mathrm{Mb}$ also has a strong UV-Vis absorbance that enables ready identification of its functional status (as determined by the redox state of its Fe-containing heme group, which mediates its oxygen binding capabilities). $\mathrm{Mb}$ has additionally been used in other investigations and its employment in this study enabled ready comparisons of our results (Table IV) to baseline values from the literature (Table VI). 
mBlue was easily encapsulated in PEO-b-PBD polymersomes formed by "thin-film rehydration" (at elevated temperatures), yielding final weight ratios of mBlue-to-polymer of 4.1 and $5.0 \mathrm{w} / \mathrm{w} \%$ when formed at 40 and $60{ }^{\circ} \mathrm{C}$, respectively; for $\mathrm{Mb}$ encapsulation, however, similar conditions only led to protein degradation. Notably, when vesicles are formed by "thin-film rehydration", hydrophilic lamellae (a.k.a. sponge-like structures) are first formed $(22,45)$; this is followed by transformation into hexagonally packed vesicles and finally into fully dispersed polymersomes $(22,45,46)$. When "thin-film rehydration" is attempted in solutions of soluble small molecules (or proteins), these water-soluble species adsorb to the surfaces of the budding lamellae, which subsequently adopt a spontaneous (or preferred) curvature. During formation, these membranes preferentially bend away from the aqueous compartment that contains the higher concentration of adsorbing species, thereby excluding the watersoluble agents from vesicle encapsulation (45). Ultimately, the input of energy can overcome this spontaneous surface tension in order to promote vesicle encapsulation. The amount of energy that is required scales with the size of the adsorbed molecule and the membrane thickness of the vesicle $(36,37$, $47,48)$. Thus, while it is easy to disrupt liposomes and enable effective small molecule and protein loading by "thin-film rehydration", the input of thermal (and/or sonic) energy only enables effective encapsulation of small molecules into polymersome suspensions.

The "direct hydration" method, by contrast, was developed as a hybrid of two other preparation methods, namely "solvent dispersion" and "homopolymer addition" (22). In the "direct hydration" protocol, the hydrophilic polymer PEG500 is used to disrupt the interactions of hydrophobic chains in the forming polymer lamellae (22). With subsequent additions of aqueous solution, self-assembly of vesicles from budding lamellae that have dispersed protein is promoted and results in improvements in aqueous encapsulation; encapsulation efficiencies as high as $37 \%$ have been observed (22). Supporting these initial studies, we generated PEM suspensions by "direct hydration" at $23{ }^{\circ} \mathrm{C}$ and measured protein encapsulation efficiencies of $>10 \%$; the encapsulated $\mathrm{Mb}$ exhibited good suspension properties and the characteristic absorption spectra of the intact protein. The final loading of Mb in these PEM suspensions, 
however, was found to be very low ( 0.3 w/w\% Mb/polymer), which was consistent with results calculated from the original paper (Table VI) (22). Upon addition of a protease solution to induce proteolysis of all surface-associated (i.e. non-specifically bound) protein, the final $\mathrm{Mb}$ composition in PEM suspensions was found to be even lower $(<0.1 \mathrm{w} / \mathrm{w} \% \mathrm{Mb} /$ polymer $)$. As the loading of therapeutic proteins within the aqueous cavities of polymersomes is ultimately the metric that must be maximized for translational applications (in order to minimize the amount of associated carrier that is introduced to a subject), it was evident that the development of a more robust encapsulation protocol was required.

By optimizing and combining various steps from multiple vesicle formation methods, a new "progressive saturation" technique was developed that enabled efficient encapsulation of functional proteins within polymersomes. Factors influencing the final concentration of protein, the relative loading level that could be achieved within the carrier (i.e. w/w\% protein/polymer), and the efficiency of protein encapsulation were systematically evaluated using $\mathrm{Mb}$ as a model protein and OB18 as the polymersome system. We found that factors such as the molecular weight of the polymer, the oxidation state and concentration of the protein, the $\mathrm{pH}$ and nature of the buffered solution, the exact polymer hydration conditions (i.e. time, temperature, and blending technique), and the number and duration of sonication steps all had effects on the concentration and the fidelity of the final polymersome-encapsulated protein product. For the optimized "progressive saturation" protocol, 5 subsequent additions of Mb solution were also made to the PEG/polymer mixture, in lieu of serially dilutions with PBS (as described in the original "direct hydration" paper (22)). The significant improvements in the final Mb-to-polymer weight ratios that were obtained (i.e. 4-6 w/w\% Mb:polymer with "progressive saturation" vs. 0.1-0.3 w/w\% by "direct hydration") suggest that the polymersome formation process is not complete during the initial addition step; further encapsulation is accomplished with each subsequent introduction of protein solution.

Notably, we found that there was a direct tradeoff between $\mathrm{Mb}$ encapsulation efficiency and the final weight ratios of Mb-to-polymer that could be achieved based on the concentrations of free $\mathrm{Mb}$ that were used for each addition step. While other studies have reported achieving both high encapsulation 
efficiencies and large loading capacities (i.e. high final weight ratios of Mb-to-polymer), it is important to underscore that these investigations did not attempt to differentiate the extent of surface-associated vs. encapsulated protein in the final nanoparticle suspensions. Aqueous encapsulation of protein is, of course, preferred in order to assure that the final product meets the original objectives for utilizing a polymersome delivery vehicle: i.e. to avoid biochemical instability, to increase circulatory half-life, to minimize adverse side effects, and to achieve controlled release of the associated protein. Larger scale batches of PEM, which were generated from $500 \mathrm{mg}$ of polymer using the "progressive saturation" method, yielded similar encapsulation results to those obtained with these small-scale batch preparations, supporting the scalability of the technique. Moreover, by employing different proteins that varied over a large range of molecular weights and sizes, including those associated with therapeutically relevant antibodies and enzymes, the robustness and the versatility of the "progressive saturation" method were established.

Using nondegradable PEO-b-PBD-based polymersomes as a model system, we demonstrated the colloidal stability of PEM suspensions at 4,23 , and $37{ }^{\circ} \mathrm{C}$ for over two weeks; the oxygen binding and release capabilities of $\mathrm{Mb}$ in these polymersome suspensions were further examined and verified to be preserved. Notably, the oxygen equilibrium curve of PEM demonstrated a slightly hyperbolic shape at low oxygen tensions as compared to that of free $\mathrm{Mb}$; parametric fitting also demonstrated a larger $\mathrm{P}_{50}$ and n (cooperativity coefficient) for PEM as compared to the unencapsulated protein. Together, these results indicate a slight reduction in oxygen binding affinity but also a mild decrease in the off-loading of oxygen at low oxygen tensions for PEM as compared to free Mb. Mechanistically this may be mediated by decreased oxygen transport across the thick polymersome membranes. Notably, the $\mathrm{P}_{50}$ and $\mathrm{n}$ of polymersome suspensions that contained both surface-associated and encapsulated Mb (PEM-SE) were of intermediate values to those of free $\mathrm{Mb}$ and pure polymersome-encapsulated $\mathrm{Mb}$ (PEM-E) obtained by proteolysis of all surface-associated protein. The explanation that membrane transport affects are most likely determining changes in oxygen binding is further supported by the results of kinetic studies that measured the oxygen binding and release of hemoglobin $(\mathrm{Hb})$ in polymersomes (49); they observed a 
decrease in the rate of $\mathrm{O}_{2}$ offloading in polymersome-encapsulated $\mathrm{Hb}$ suspensions, in RBCs, as well as with PEG-conjugated liposome-encapsulated Hbs (LEHs) as compared to acellular (free) Hb.

\section{CONCLUSIONS}

Conventional vesicle formation methods may be used to encapsulate small molecules within polymersomes (as demonstrated in this study using mblue); but, they do not yield consistent, reproducible, or scalable encapsulation of functional proteins in neutrally charged, fully PEGylated and nanoscale polymersomes. By optimizing and combining various steps from several of these established protocols, we introduce a novel "progressive saturation" technique that achieves increased encapsulation of functional protein in polymersomes of varying size, PEG length, and membrane thickness. We demonstrate a tradeoff between the degree of polymersome loading (i.e. weight percentage of protein-topolymer) and the encapsulation efficiency of protein (with respect to the initial quantity) that may be achieved. Moreover, we introduce a novel proteolysis step that enables accurate quantification of the amounts of both encapsulated protein (i.e. the desired outcome) as well as that of surface-associated (i.e. non-specifically bound) product that is obtained in polymersome suspensions. Previous studies have reported that large amounts of protein may be loaded within polymersomes and at high efficiencies, using conventional liposome encapsulation techniques. They had not, however, sought to differentiate between encapsulated and surface-associated protein, which may account for discrepancies in their observations as compared to the results presented here. Importantly, we have also demonstrated that "progressive saturation" enables stable encapsulation of functional protein; it may be further employed to maximize the aqueous encapsulation of many different proteins that vary over a large range of molecular weights and sizes, including those associated with therapeutically relevant antibodies and enzymes. In summary, "progressive saturation" is a robust, scalable, and generalizable technique for generating polymersomeencapsulated proteins in quantities and at efficiencies that may enable further translational development. 


\section{ACKNOWLEDGMENTS}

This work was partially supported by grants from the National Institutes of Health (1R43CA15952701A1 and 1R43AI096605-01) as well as awards from the Kentucky Science and Technology Corporation (KSTC-18-OCIS-194, KSTC-184-512-12-135, KSTC-184-512-13-156). PPG acknowledges support from the Charles W. and Jennifer C. Johnson Clinical Investigator fund and from the Kathryn Fox Samway Foundation. ZT is thankful for the generous support of the Misrock Foundation.

\section{CONFLICTS OF INTEREST}

Dr. Ghoroghchian is a co-founder and the previous Chief Scientific Officer of Vindico Pharmaceuticals, Inc, where he directed research efforts. He currently serves as a consultant and as the head of the company's scientific advisory board. The authors declare that they have no conflicts of interest. 


\section{REFERENCES}

1. Lundstrom K. An overview on GPCRs and drug discovery: structure-based drug design and structural biology on GPCRs. Methods Mol Biol. 2009;552:51-66.

2. Overington JP, Al-Lazikani B, Hopkins AL. How many drug targets are there? Nat Rev Drug Discov. 2006;5(12):993-6.

3. Thompson DB, Cronican JJ, Liu DR. Chapter twelve - Engineering and Identifying Supercharged Proteins for Macromolecule Delivery into Mammalian Cells. In: Wittrup KD, Gregory LV, editors. Methods in Enzymology. Volume 503: Academic Press; 2012. p. 293-319.

4. Carter PJ. Introduction to current and future protein therapeutics: a protein engineering perspective. Exp Cell Res. 2011;317(9):1261-9.

5. Leader B, Baca QJ, Golan DE. Protein therapeutics: a summary and pharmacological classification. Nat Rev Drug Discov. 2008;7(1):21-39.

6. Yewle JN, Puleo DA, Bachas LG. Bifunctional bisphosphonates for delivering PTH (1-34) to bone mineral with enhanced bioactivity. Biomaterials. 2013;34(12):3141-9.

7. Ghoroghchian PP, Frail PR, Susumu K, Blessington D, Brannan AK, Bates FS, et al. Near-infraredemissive polymersomes: Self-assembled soft matter for in vivo optical imaging. Proc Natl Acad Sci USA. 2005;102(8):2922-7.

8. Qi W, Ghoroghchian PP, Li G, Hammer DA, Therien MJ. Aqueous self-assembly of poly(ethylene oxide)-block-poly([varepsilon]-caprolactone) (PEO-b-PCL) copolymers: disparate diblock copolymer compositions give rise to nano- and meso-scale bilayered vesicles. Nanoscale. 2013;5(22):10908-15.

9. Ghoroghchian PP, Therien MJ, Hammer DA. In vivo fluorescence imaging: a personal perspective. Wiley Interdisciplinary Rev Nanomed Nanobiotechnol. 2009;1(2):156-67.

10. Ghoroghchian PP, Frail PR, Susumu K, Park T-H, Wu SP, Uyeda HT, et al. Broad Spectral Domain Fluorescence Wavelength Modulation of Visible and Near-Infrared Emissive Polymersomes. J Am Chem Soc. 2005;127(44):15388-90.

11. Ghoroghchian PP, Li G, Levine DH, Davis KP, Bates FS, Hammer DA, et al. Bioresorbable Vesicles Formed through Spontaneous Self-Assembly of Amphiphilic Poly(ethylene oxide)-blockpolycaprolactone. Macromolecules. 2006;39(5):1673-5.

12. Wu SP, Lee I, Ghoroghchian PP, Frail PR, Zheng G, Glickson JD, et al. Near-Infrared Optical Imaging of B16 Melanoma Cells via Low-Density Lipoprotein-Mediated Uptake and Delivery of High Emission Dipole Strength Tris[(porphinato)zinc(II)] Fluorophores. Bioconjugate Chem. 2005;16(3):54250.

13. Levine DH, Ghoroghchian PP, Freudenberg J, Zhang G, Therien MJ, Greene MI, et al. Polymersomes: A new multi-functional tool for cancer diagnosis and therapy. Methods. 2008;46(1):2532.

14. Meng F, Zhong Z, Feijen J. Stimuli-Responsive Polymersomes for Programmed Drug Delivery. Biomacromolecules. 2009;10(2):197-209.

15. Discher BM, Won Y-Y, Ege DS, Lee JC-M, Bates FS, Discher DE, et al. Polymersomes: Tough Vesicles Made from Diblock Copolymers. Science. 1999;284(5417):1143-6.

16. Liu G, Ma S, Li S, Cheng R, Meng F, Liu H, et al. The highly efficient delivery of exogenous proteins into cells mediated by biodegradable chimaeric polymersomes. Biomaterials. 2010;31(29):7575-85.

17. Weiss B, Schneider M, Muys L, Taetz S, Neumann D, Schaefer UF, et al. Coupling of Biotin-(poly(ethylene glycol))amine to Poly(d,I-lactide-co-glycolide) Nanoparticles for Versatile Surface Modification. Bioconjugate Chem. 2007;18(4):1087-94. 
18. Wong CK, Laos AJ, Soeriyadi AH, Wiedenmann J, Curmi PMG, Gooding JJ, et al. Polymersomes Prepared from Thermoresponsive Fluorescent Protein-Polymer Bioconjugates: Capture of and Report on Drug and Protein Payloads. Angew Chem Int Ed. 2015;54(18):5317-22.

19. Noor M, Dworeck T, Schenk A, Shinde P, Fioroni M, Schwaneberg U. Polymersome surface decoration by an EGFP fusion protein employing Cecropin A as peptide "anchor". J Biotechnol. 2012;157(1):31-7.

20. Hammer DA, Robbins GP, Haun JB, Lin JJ, Qi W, Smith LA, et al. Leuko-polymersomes. Faraday Discuss. 2008;139:129-420.

21. Lin JJ, Ghoroghchian PP, Zhang Y, Hammer DA. Adhesion of Antibody-Functionalized Polymersomes. Langmuir. 2006;22(9):3975-9.

22. O'Neil CP, Suzuki T, Demurtas D, Finka A, Hubbell JA. A Novel Method for the Encapsulation of Biomolecules into Polymersomes via Direct Hydration. Langmuir. 2009;25(16):9025-9.

23. Christian NA, Milone MC, Ranka SS, Li G, Frail PR, Davis KP, et al. Tat-Functionalized NearInfrared Emissive Polymersomes for Dendritic Cell Labeling. Bioconjugate Chem. 2007;18(1):31-40.

24. Marsden HR, Quer CB, Sanchez EY, Gabrielli L, Jiskoot W, Kros A. Detergent-Aided Polymersome Preparation. Biomacromolecules. 2010;11(4):833-8.

25. Lee JS, Feijen J. Polymersomes for drug delivery: Design, formation and characterization. J Controlled Release. 2012;161(2):473-83.

26. Kita-Tokarczyk K, Grumelard J, Haefele T, Meier W. Block copolymer vesicles-using concepts from polymer chemistry to mimic biomembranes. Polymer. 2005;46(11):3540-63.

27. Kremer $\mathrm{JMH}$, Van der Esker MW, Pathmamanoharan C, Wiersema PH. Vesicles of variable diameter prepared by a modified injection method. Biochemistry. 1977;16(17):3932-5.

28. Weinberger A, Tsai F-C, Koenderink Gijsje H, Schmidt Thais F, Itri R, Meier W, et al. Gel-Assisted Formation of Giant Unilamellar Vesicles. Biophysical J. 2013;105(1):154-64.

29. Photos PJ, Bacakova L, Discher B, Bates FS, Discher DE. Polymer vesicles in vivo: correlations with PEG molecular weight. J Controlled Release. 2003;90(3):323-34.

30. Lee JCM, Bermudez H, Discher BM, Sheehan MA, Won Y-Y, Bates FS, et al. Preparation, stability, and in vitro performance of vesicles made with diblock copolymers. Biotechnol Bioeng. 2001;73(2):13545.

31. Christian DA, Garbuzenko OB, Minko T, Discher DE. Polymer Vesicles with a Red Cell-like Surface Charge: Microvascular Imaging and in vivo Tracking with Near-Infrared Fluorescence. Macromol Rapid Commun. 2010;31(2):135-41.

32. Rameez S, Bamba I, Palmer AF. Large Scale Production of Vesicles by Hollow Fiber Extrusion: A Novel Method for Generating Polymersome Encapsulated Hemoglobin Dispersions. Langmuir. 2010;26(7):5279-85.

33. Lomas H, Johnston APR, Such GK, Zhu Z, Liang K, Van Koeverden MP, et al. Polymersome-Loaded Capsules for Controlled Release of DNA. Small. 2011;7(14):2109-19.

34. Wang L, Chierico L, Little D, Patikarnmonthon N, Yang Z, Azzouz M, et al. Encapsulation of Biomacromolecules within Polymersomes by Electroporation. Angew Chem Int Ed. 2012;51(44):11122-5.

35. Aranda-Espinoza $\mathrm{H}$, Bermudez $\mathrm{H}$, Bates FS, Discher DE. Electromechanical Limits of Polymersomes. Phys Rev Lett. 2001;87(20):208301.

36. Ghoroghchian PP, Frail PR, Li G, Zupancich JA, Bates FS, Hammer DA, et al. Controlling Bulk Optical Properties of Emissive Polymersomes through Intramembranous Polymer-Fluorophore Interactions. Chem Mater. 2007;19(6):1309-18.

37. Duncan TV, Ghoroghchian PP, Rubtsov IV, Hammer DA, Therien MJ. Ultrafast Excited-State Dynamics of Nanoscale Near-Infrared Emissive Polymersomes. J Chem Soc. 2008;130(30):9773-84.

38. Dimino ML, Palmer AF. Purification of bovine hemoglobin via fast performance liquid chromatography. J Chromatogr B. 2007;856(1-2):353-7. 
39. Arifin DR, Palmer AF. Stability of Liposome Encapsulated Hemoglobin Dispersions. Artif Cells Blood Substit Immobil Biotechnol. 2005;33(2):113-36.

40. Dimino ML, Palmer AF. High $\mathrm{O} 2$ affinity hemoglobin-based oxygen carriers synthesized via polymerization of hemoglobin with ring-opened 2-chloroethyl- $\beta$-D-fructopyranoside and 1-o-octyl- $\beta$-Dglucopyranoside. Biotechnol Bioeng. 2007;97(3):462-72.

41. Rameez S, Alosta H, Palmer AF. Biocompatible and Biodegradable Polymersome Encapsulated Hemoglobin: A Potential Oxygen Carrier. Bioconjugate Chem. 2008;19(5):1025-32.

42. Li S, Nickels J, Palmer AF. Liposome-encapsulated actin-hemoglobin (LEAcHb) artificial blood substitutes. Biomaterials. 2005;26(17):3759-69.

43. Arifin DR, Palmer AF. Polymersome Encapsulated Hemoglobin: A Novel Type of Oxygen Carrier. Biomacromolecules. 2005;6(4):2172-81.

44. Pangu GD, Davis KP, Bates FS, Hammer DA. Ultrasonically Induced Release from Nanosized Polymer Vesicles. Macromolecular Biosci. 2010;10(5):546-54.

45. Battaglia G, Ryan AJ. The evolution of vesicles from bulk lamellar gels. Nature Materials 2005;4:869-76.

46. Battaglia G, Ryan AJ. Effect of Amphiphile Size on the Transformation from a Lyotropic Gel to a Vesicular Dispersion. Macromolecules. 2005;39(2):798-805.

47. Sanson C, Le Meins JF, Schatz C, Soum A, Lecommandoux S. Temperature responsive poly(trimethylene carbonate)-block-poly(l-glutamic acid) copolymer: polymersomes fusion and fission. Soft Matter. 2010;6(8):1722-30.

48. Baumgart T, Hess ST, Webb WW. Imaging coexisting fluid domains in biomembrane models coupling curvature and line tension. Nature. 2003;425(6960):821-4.

49. Rameez S, Banerjee U, Fontes J, Roth A, Palmer AF. The Reactivity of Polymersome Encapsulated Hemoglobin with Physiologically Important Gaseous Ligands: Oxygen, Carbon Monoxide and Nitric Oxide. Macromolecules. 2012;45(5):2385-9.

50. Zhang J, Wu L, Meng F, Wang Z, Deng C, Liu H, et al. pH and Reduction Dual-Bioresponsive Polymersomes for Efficient Intracellular Protein Delivery. Langmuir. 2012;28(4):2056-65.

51. Cheng R, Meng F, Ma S, Xu H, Liu H, Jing X, et al. Reduction and temperature dual-responsive crosslinked polymersomes for targeted intracellular protein delivery. J Mater Chem. 2011;21(47):1901320.

52. van Dongen SFM, Nallani M, Cornelissen JJLM, Nolte RJM, van Hest JCM. A Three-Enzyme Cascade Reaction through Positional Assembly of Enzymes in a Polymersome Nanoreactor. Chem Eur J. 2009;15(5):1107-14.

53. Hvasanov D, Wiedenmann J, Braet F, Thordarson P. Induced polymersome formation from a diblock PS-b-PAA polymervia encapsulation of positively charged proteins and peptides. Chem Comm. 2011;47(22):6314-6. 


\section{TABLE LEGEND}

Table I. Properties of poly(ethylene oxide)-block-poly(butadiene) (PEO-b-PBD) diblock copolymers and their subsequent polymersome formulations used for small molecule and protein encapsulation

Table II: Summary of the factors studied for optimization of the direct hydration protocol and to develop the progressive saturation method for encapsulation of proteins in polymersomes.

Table III. Properties of OB18-based PEM suspensions prepared using the "progressive saturation" technique.

Table IV. Encapsulation of proteins in OB29-based polymersomes using the "progressive saturation" technique.

Table V. $\mathrm{P}_{50}$ values for free myoglobin $(\mathrm{Mb})$ as well as polymersome-encapsulated $\mathrm{Mb}$ prior to proteolysis (PEM-SE) and after pronase treatment (PEM-E), as obtained from $\mathrm{O}_{2}$ equilibrium curves. PEM-SE and PEM-E samples were prepared by the "progressive saturation" technique.

Table VI. Summary of reported studies that have examined encapsulation of proteins in polymersomes. 


\section{FIGURE LEGEND}

Scheme 1. Schematic depicting: A) amphiphillic diblock copolymers, water-insoluble agents, and watersoluble species that may be encapsulated within polymersomes. The B) "thin-film rehydration", C) “direct hydration", and D) modified "progressive saturation" methods for encapsulation of water-soluble species within the aqueous cavities of polymersomes.

Figure 1. Incorporation of $\mathrm{mBlue}$ and $\mathrm{Mb}$ in polymersome suspensions, using conventional liposome formation techniques. (A) Encapsulation of mBlue in OB18 polymersomes by "thin-film rehydration" at $40{ }^{\circ} \mathrm{C}$ and $60{ }^{\circ} \mathrm{C}$; (B) Encapsulation of mBlue in OB18 polymersomes by "direct hydration" at $23{ }^{\circ} \mathrm{C}$. (C) Encapsulation of $\mathrm{Mb}$ in $\mathrm{OB} 18$ polymersomes by "thin-film rehydration" at $23{ }^{\circ} \mathrm{C}$. (D) Encapsulation of $\mathrm{Mb}$ in OB18 polymersomes by "direct hydration" at $23^{\circ} \mathrm{C}$. Polymersome were subjected to proteolysis to remove any surface-associated (free) Mb in suspension. Mb concentrations in each sample were analyzed using UV-Vis spectrophotometry. Data represent mean values and error bars denote standard deviations of the mean for an $\mathrm{n}=5$ experimental replicates. $(* * * p<0.001)$.

Figure 2. Optimization of various steps in the "direct hydration" protocol in order to improve the encapsulation of $\mathrm{Mb}$ in $\mathrm{OB} 18$ polymersomes (as determined by the final weight percentage of Mb-topolymer (i.e. w/w\% Mb/polymer) that could be obtained in PEM suspensions). A) The effects of utilizing an organic solvent vs. the addition of heat during the first step of the "direct hydration" protocol. B) The effects of the oxidation state of Mb used for polymersome encapsulation and for each subsequent addition step. C) The rate of $\mathrm{Mb}$ oxidation (as expressed by the percentage of metmyoglobin (i.e. \%metMb) formed over time) as a function of $\mathrm{Mb}$ exposure to different solution conditions. D) The effects of sonication time after each dilution step. E) Optimization of the proteolysis time to remove all surface- 
associated $\mathrm{Mb}$ from polymersome suspensions; note: “\% Mb loss” denotes surface-associated Mb fraction and not total $\mathrm{Mb}$; samples were proteolyzed for $18 \mathrm{~h}$ to remove surface-associated $\mathrm{Mb}$ followed by UVVis quantification. F) Final weight percentage of Mb-to-polymer (i.e. “w/w\% Mb/polymer”) vs. Mb encapsulation efficiency (i.e. “\%Mb EE") obtained by tuning the relative volume of $\mathrm{Mb}$ suspension (150 $\mathrm{mg} / \mathrm{mL} \mathrm{Mb}$ ) to PBS used in each addition step. Data represent mean values and error bars denote standard deviations of the mean for an $\mathrm{n}=5$ experimental replicates. $(* \mathrm{p}<0.05$ and $* * \mathrm{p}<0.01)$.

Figure 3. Characterizations of the final polymersome-encapsulated protein suspensions formed by using the "progressive saturation" technique. A) The average hydrodynamic diameter of particles in OB18-and OB29-based PEM suspensions as assessed by DLS. Cryo-TEM images of vesicles in B) OB18- and C) OB29-based PEM suspensions; scale bar $=50$ and $20 \mathrm{~nm}$ in Fig. 3B and 3C, respectively. D) Average hydrodynamic diameters of particles (as determined by DLS) in OB18-based PEM suspensions as a function of temperature $\left(4,23\right.$, and $\left.37^{\circ} \mathrm{C}\right)$ and time. E) Final weight percentage of Mb-to-polymer (i.e. “w/w\% Mb/polymer") of particles in OB18-based PEM suspensions as a function of temperature $(4,23$, and $37{ }^{\circ} \mathrm{C}$ ) and time. F) Oxygen equilibrium curves for free oxyMb and oxygenated OB18-based PEM suspensions. Data represent mean values and error bars denote standard deviations of the mean for an $\mathrm{n}=$ 5 experimental replicates. 
Table I. Properties of poly(ethylene oxide)-block-poly(butadiene) (PEO-b-PBD) diblock copolymers and their polymersome formulations used for small molecule and protein encapsulation $(36,37)$.

\begin{tabular}{cccccc}
\hline $\begin{array}{c}\text { Copolymer } \\
\text { Name }\end{array}$ & $\begin{array}{c}\text { Mn* } \times 10^{3} \\
\text { PEO-b-PBD }\end{array}$ & $\begin{array}{c}\text { Mw } \\
(\mathrm{kg} / \mathrm{mol})\end{array}$ & P.D.* & $\begin{array}{c}\text { Membrane } \\
\text { Thickness }(\mathrm{nm})\end{array}$ & $\begin{array}{c}\text { Vesicle } \\
\text { Diameter }(\mathrm{nm})\end{array}$ \\
\hline OB18 & $3.9-\mathrm{b}-6.5$ & 10400 & 1.10 & 14.8 & 205 \\
OB29 & $1.3-\mathrm{b}-2.5$ & 3800 & 1.04 & 9.6 & 132 \\
\hline
\end{tabular}

*Mn denotes number-average molecular weight and P.D. is the polydispersity index of the polymer.

Table II: Summary of the factors studied for optimization of the direct hydration protocol and to develop the progressive saturation method for encapsulation of proteins in polymersomes.

\begin{tabular}{|c|c|c|c|c|c|c|}
\hline PROTOCOL & \multicolumn{5}{|l|}{ CONDITIONS } & RESULTS \\
\hline $\begin{array}{l}\text { Original Direct Hydration } \\
\text { Protocol }\end{array}$ & \multicolumn{5}{|c|}{$\begin{array}{l}\text { STEP 1: Heating of polymer and PEG500 to } 95{ }^{\circ} \mathrm{C} \text { followed by } \\
\text { cooling to RT } \\
\text { STEP 2: Addition of protein solution followed by vortexing mix } \\
\text { sample } \\
\text { STEP 3: Encapsulation driven by serial dilution of protein } \\
\text { solution with PBS } \\
\text { STEP 4: Removal of uncapsulated protein by dialysis }\end{array}$} & Figure 1D \\
\hline $\begin{array}{l}\text { Optimization of Direct } \\
\text { Hydration Protocol }\end{array}$ & & \multicolumn{4}{|c|}{$\begin{array}{l}\text { Steps of } \\
\text { Original } \\
\text { Direct } \\
\text { Hydration } \\
\text { Protocol } \\
\text { that were } \\
\text { Modified }\end{array}$} & \\
\hline Blending Method & $\begin{array}{l}\text { Heating of polymer and PEG for } 1 \mathrm{~h} \text { at } 95{ }^{\circ} \mathrm{C} \\
\text { followed by cooling to room temperature } \\
\text { Dissolving polymer and PEG in DCM followed by } \\
\text { solvent evaporation }\end{array}$ & $\mathbf{X}$ & & & & Figure 2A \\
\hline $\begin{array}{l}\text { Oxidation State of Mb } \\
\text { Solution that is Added }\end{array}$ & $\begin{array}{l}\text { Utilizing oxyMb for encapsulation } \\
\text { Utilizing metMb for encapsulation }\end{array}$ & & $\mathbf{X}$ & & & Figure 2B \\
\hline $\begin{array}{l}\text { Effect of Sonication and } \\
\text { Temperature on } \mathrm{Mb} \\
\text { Oxidation }\end{array}$ & $\begin{array}{l}\text { Heating the oxyMb solution at } 40^{\circ} \mathrm{C} \\
\text { Heating the oxyMb solution at } 50^{\circ} \mathrm{C} \\
\text { Sonication the oxyMb solution at } 40^{\circ} \mathrm{C}\end{array}$ & & $\mathbf{X}$ & & & Figure 2C \\
\hline $\begin{array}{l}\text { Mixing Technique for } \\
\text { Addition of Protein } \\
\text { Solution }\end{array}$ & $\begin{array}{l}\text { Sonication for } 0 \mathrm{~min} \text { after each dilution step } \\
\text { Sonication for } 15 \mathrm{~min} \text { after each dilution step } \\
\text { Sonication for } 30 \mathrm{~min} \text { after each dilution step } \\
\text { Sonication for } 45 \mathrm{~min} \text { after each dilution step } \\
\text { Sonication for } 60 \mathrm{~min} \text { after each dilution step }\end{array}$ & & & $X$ & & Figure 2D \\
\hline $\begin{array}{l}\text { Removal of } \\
\text { Unencapsulated Protein }\end{array}$ & $\begin{array}{l}\text { Dialysis only; no proteolysis treatment } \\
\text { Dialysis and treatment with pronase for } 2 \mathrm{~h}\end{array}$ & & & & $\mathbf{X}$ & Figure 2E \\
\hline $\begin{array}{l}\text { Mb Encapsulation } \\
\text { Efficiency vs. Ratio of } \\
\text { Mb:PBS that is Added }\end{array}$ & $\begin{array}{l}\mathrm{Mb}: P B S=10: 180 \\
\mathrm{Mb}: P B S=20: 170 \\
M b: P B S=40: 150 \\
M b: P B S=90: 100 \\
M b: P B S=190: 0\end{array}$ & & & $\mathbf{X}$ & $\mathbf{X}$ & Figure 2F \\
\hline
\end{tabular}


Table III. Properties of OB18-based PEM suspensions prepared using the "progressive saturation" technique.

\begin{tabular}{lcc}
\hline \multicolumn{1}{|c}{ PEM Properties } & $\begin{array}{c}\text { Before } \\
\text { Proteolysis }\end{array}$ & $\begin{array}{c}\text { After } \\
\text { Proteolysis }\end{array}$ \\
\hline Final w/w\% Mb/Polymer (by UV-vis) & $6.08 \pm 0.75$ & $3.17 \pm 0.54$ \\
\hline Final w/w\% Mb/Polymer (by ICP-OES) & $7.96 \pm 0.91$ & $5.10 \pm 0.62$ \\
\hline \% metMb & $7.98 \pm 1.90$ & $5.55 \pm 0.97$ \\
\hline Size (d.nm) & 205 & 205 \\
\hline
\end{tabular}

Table IV. Encapsulation of proteins in OB29-based polymersomes using the "progressive saturation" technique.

\begin{tabular}{|c|c|c|c|c|c|c|c|c|c|}
\hline Protein & $\begin{array}{l}\text { MW* } \\
\text { (kDa) }\end{array}$ & $\begin{array}{l}\text { Before } \\
\text { or } \\
\text { After } \\
\text { Pronase }\end{array}$ & $\begin{array}{l}\text { Final } \\
\text { Protein } \\
\text { (mg/mL) } \\
\text { by BCA }\end{array}$ & $\begin{array}{l}\text { w/w\% } \\
\text { Protein } \\
\text { /Polymer } \\
\text { by BCA }\end{array}$ & $\begin{array}{l}\text { EE* } \\
(\%)\end{array}$ & $\begin{array}{l}\text { Final } \\
\text { Protein } \\
\text { (mg/mL) } \\
\text { by UV-Vis }\end{array}$ & $\begin{array}{l}\text { w/w\% } \\
\text { Protein/ } \\
\text { Polymer } \\
\text { by UV-Vis }\end{array}$ & $\begin{array}{l}\text { Final } \\
\text { Protein } \\
\text { (mg/mL) } \\
\text { by ICP-OES }\end{array}$ & $\begin{array}{l}\text { w/w\% } \\
\text { Protein/ } \\
\text { Polymer } \\
\text { by ICP-OES }\end{array}$ \\
\hline \multirow[t]{2}{*}{ Myoglobin } & \multirow[t]{2}{*}{17} & Before & $2.68 \pm 0.75$ & $13.39 \pm 3.75$ & 4.70 & $2.21 \pm 1.19$ & $11.07 \pm 5.97$ & $3.82 \pm 1.07$ & $19.10 \pm 5.36$ \\
\hline & & After & $1.98 \pm 0.43$ & $9.19 \pm 2.15$ & 3.48 & $1.13 \pm 0.44$ & $5.64 \pm 2.21$ & $2.06 \pm 0.80$ & $10.31 \pm 3.98$ \\
\hline \multirow[t]{2}{*}{ Hemoglobin } & \multirow[t]{2}{*}{64} & Before & $5.26 \pm 1.00$ & $20.79 \pm 6.87$ & 7.30 & $3.14 \pm 1.02$ & $11.95 \pm 2.21$ & $8.00 \pm 2.35$ & $31.77 \pm 12.50$ \\
\hline & & After & $3.38 \pm 0.46$ & $13.30 \pm 3.70$ & 4.67 & $2.16 \pm 0.02$ & $8.40 \pm 1.13$ & $4.90 \pm 1.20$ & $19.37 \pm 6.59$ \\
\hline \multirow{2}{*}{$\begin{array}{l}\text { Bovine Serum } \\
\text { Albumin }\end{array}$} & \multirow[t]{2}{*}{66} & Before & $3.53 \pm 2.38$ & $15.60 \pm 11.02$ & 13.69 & & & & \\
\hline & & After & $3.49 \pm 1.13$ & $15.42 \pm 5.15$ & 13.53 & & & & \\
\hline \multirow[t]{2}{*}{ IgG } & \multirow[t]{2}{*}{150} & Before & $5.54 \pm 2.03$ & $35.99 \pm 13.21$ & 94.72 & & & & \\
\hline & & After & $3.20 \pm 1.51$ & $21.23 \pm 9.39$ & 55.88 & & & & \\
\hline \multirow[t]{2}{*}{ Catalase } & \multirow[t]{2}{*}{250} & Before & $5.42 \pm 3.10$ & $30.79 \pm 16.09$ & 32.41 & & & & \\
\hline & & After & $2.28 \pm 0.70$ & $13.09 \pm 3.27$ & 13.77 & & & & \\
\hline \multirow[t]{2}{*}{ Fibrinogen } & \multirow[t]{2}{*}{340} & Before & $5.37 \pm 0.76$ & $26.10 \pm 3.49$ & 27.48 & & & & \\
\hline & & After & $3.05 \pm 0.39$ & $14.82 \pm 1.72$ & 15.60 & & & & \\
\hline \multirow[t]{2}{*}{ Apoferritin } & \multirow[t]{2}{*}{450} & Before & $1.99 \pm 1.02$ & $8.51 \pm 4.28$ & 17.92 & & & & \\
\hline & & After & $1.73 \pm 1.23$ & $7.57 \pm 5.73$ & 15.94 & & & & \\
\hline
\end{tabular}

*MW - molecular weight; EE - encapsulation efficiency 
Table V. Values of $\mathrm{P}_{50}$ (binding affinity) and $\mathrm{n}$ (cooperativity coefficient) for free myoglobin $(\mathrm{Mb})$ as well as polymersome-encapsulated $\mathrm{Mb}$ prior to proteolysis (PEM-SE) and after pronase treatment (PEM-E), as obtained from $\mathrm{O}_{2}$ equilibrium curves. PEM-SE and PEM-E samples were prepared by the "progressive saturation" technique.

\begin{tabular}{ccc} 
Sample & $\mathbf{P}_{50}(\mathrm{~mm} \mathrm{Hg})$ & $n$ \\
\hline Mb & $2.00 \pm 0.01$ & $0.79486 \pm 0.00452$ \\
PEM-SE & $7.95 \pm 0.30$ & $0.7951 \pm 0.0281$ \\
PEM-E & $17.14 \pm 0.27$ & $1.5683 \pm 0.039$ \\
\hline
\end{tabular}

Table VI. Summary of reported studies that have examined encapsulation of proteins in polymersomes.

\begin{tabular}{|c|c|c|c|c|c|c|c|}
\hline $\begin{array}{l}\text { Block } \\
\text { copolymer }\end{array}$ & Protein & $\begin{array}{l}\text { PSM* size } \\
D[n m]\end{array}$ & $\begin{array}{l}\text { PSM }^{*} \text { size } \\
\text { after loading } \\
\text { D }[\mathrm{nm}]\end{array}$ & $\begin{array}{l}\text { Protein } \\
\text { Encapsulatio } \\
\mathrm{n}[\mathrm{mg} / \mathrm{mL}]\end{array}$ & $\begin{array}{l}\text { Protein loading, } \\
\text { w/w\% } \\
\text { protein/polymer }\end{array}$ & EE*, \% & Ref. \\
\hline \multirow{2}{*}{$\begin{array}{l}\text { PEG-SS-b- } \\
\text { PDEAEMA }\end{array}$} & $\mathrm{CC}$ & 55 & 59 & 0.010 & 5.0 & 100 & \multirow{2}{*}{ (50) } \\
\hline & BSA & 55 & 49 & 0.008 & 4.0 & 80.6 & \\
\hline \multirow{4}{*}{$\begin{array}{l}\text { PEG-B-PAAc-b- } \\
\text { PNIPAM }\end{array}$} & BSA & 162 & 150 & 2.025 & 40.5 & 81 & \multirow{4}{*}{ (51) } \\
\hline & $\mathrm{CC}$ & 162 & 155 & 2.000 & 40.0 & 80 & \\
\hline & Lys & 162 & 149 & 1.615 & 32.3 & 64.6 & \\
\hline & Ova & 162 & 147 & 2.210 & 44.2 & 88.3 & \\
\hline \multirow{5}{*}{$\begin{array}{l}\text { PEG-b-PCL- } \\
\text { PDEAEMA }\end{array}$} & BSA & 154 & 146 & 0.098 & 19.6 & 78.5 & \multirow{5}{*}{ (16) } \\
\hline & $\mathrm{CC}$ & 154 & 164 & 0.112 & 22.3 & 89.1 & \\
\hline & Lys & 154 & 150 & 0.105 & 21.0 & 84.3 & \\
\hline & Ova & 154 & 113 & 0.106 & 21.2 & 84.7 & \\
\hline & $\lg G$ & 154 & 158 & 0.112 & 22.4 & 89.6 & \\
\hline PEO-b-PCL & Hb (Human) & 100 & $110-140$ & & & $2.0-12.0$ & (41) \\
\hline PEO-b-PLA & $\mathrm{Hb}$ (Bovine) & 100 & $110-140$ & & & $4.0-20.0$ & (41) \\
\hline \multirow{2}{*}{ PEO-b-PBD } & $\mathrm{Hb}$ & 100 & 100 & 0.081 & 8.1 & 2.7 & \multirow{2}{*}{ (43) } \\
\hline & & 100 & 100 & 0.365 & 36.5 & 12 & \\
\hline \multirow{4}{*}{ PEO-b-PPS } & Ova & 200 & & 0.006 & 0.06 & $9 \pm 8$ & \multirow{4}{*}{$(22)$} \\
\hline & Ova & 200 & & 0.024 & 0.24 & $37 \pm 10$ & \\
\hline & BSA & 200 & & 0.128 & 1.28 & $19 \pm 5$ & \\
\hline & v-Globulin & 200 & & 0.050 & 0.50 & $15 \pm 5$ & \\
\hline \multirow{4}{*}{ PMPC-b-PDPA } & BSA & 110 & $110-120$ & 0.309 & 3.09 & 12.37 & \multirow{4}{*}{ (34) } \\
\hline & $\lg G$ & 110 & $110-120$ & 0.0005 & 0.0045 & 9.00 & \\
\hline & $\mathrm{Mb}$ & 110 & $110-120$ & 0.199 & 1.99 & 7.97 & \\
\hline & Lz & 110 & $110-120$ & 0.159 & 1.59 & 6.36 & \\
\hline \multirow{3}{*}{ PS-PIAT } & GOX & & & 0.625 & 125.0 & 25.00 & \multirow{3}{*}{ (52) } \\
\hline & CalB & & & 0.340 & 68.0 & 17.00 & \\
\hline & HRP & & & 0.625 & 125.0 & 25.00 & \\
\hline \multirow{3}{*}{ PS-b-PAA } & $\mathrm{CC}$ & & & & & 66.00 & \multirow{3}{*}{ (53) } \\
\hline & Poly-L-Lysine & & & & & & \\
\hline & GFP & & & & & 35.00 & \\
\hline
\end{tabular}

*PSM - polymersome; EE - encapsulation efficiency; the full names of all polymer formulations can be found in the Abbreviations section of the manuscript. 

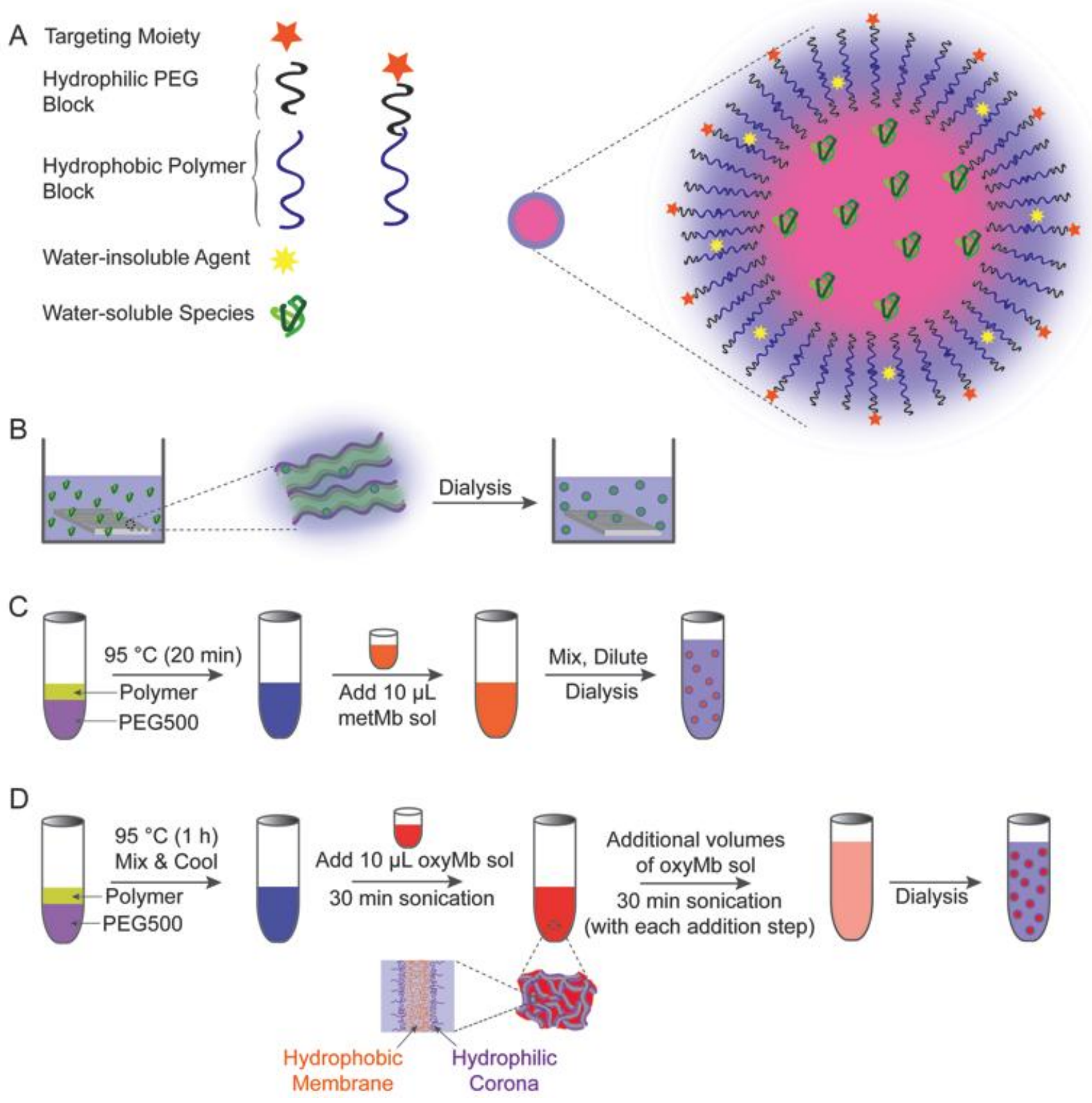

Scheme 1. Schematic depicting: A) amphiphillic diblock copolymers, water-insoluble agents, and watersoluble species that may be encapsulated within polymersomes. The B) "thin-film rehydration", C) "direct hydration", and D) modified "progressive saturation" methods for encapsulation of watersoluble species within the aqueous cavities of polymersomes. 
A

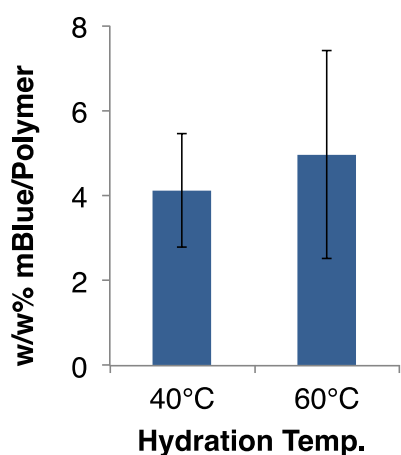

Hydration Temp.
B

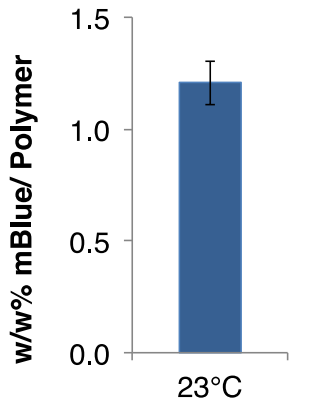

Hydration Temp
C

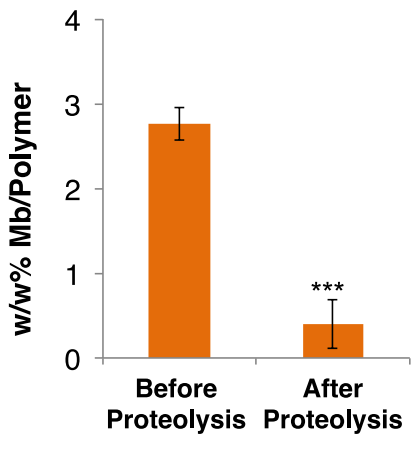

D

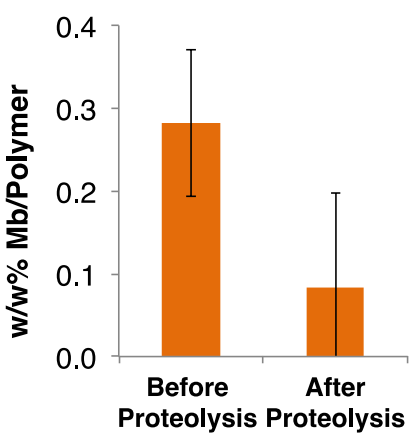

Figure 1. Incorporation of mBlue and $\mathrm{Mb}$ in polymersome suspensions, using conventional liposome formation techniques. (A) Encapsulation of mBlue in OB18 polymersomes by "thin-film rehydration" at $40{ }^{\circ} \mathrm{C}$ and $60{ }^{\circ} \mathrm{C}$; (B) Encapsulation of mBlue in OB18 polymersomes by "direct hydration" at $23^{\circ} \mathrm{C}$. (C) Encapsulation of $\mathrm{Mb}$ in OB18 polymersomes by "thin-film rehydration" at $23^{\circ} \mathrm{C}$. (D) Encapsulation of $\mathrm{Mb}$ in OB18 polymersomes by "direct hydration" at $23{ }^{\circ} \mathrm{C}$. Polymersome were subjected to proteolysis to remove any surface-associated (free) $\mathrm{Mb}$ in suspension. $\mathrm{Mb}$ concentrations in each sample were analyzed using UV-Vis spectrophotometry. Data represent mean values and error bars denote standard deviations of the mean for an $\mathrm{n}=5$ experimental replicates. $\left({ }^{* * *} p<0.001\right)$. 
A

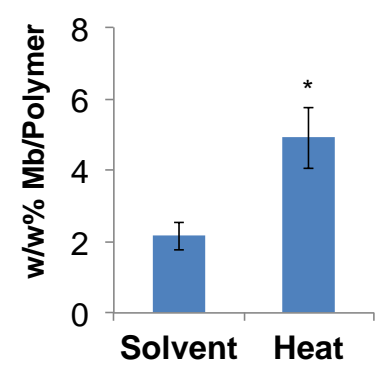

C

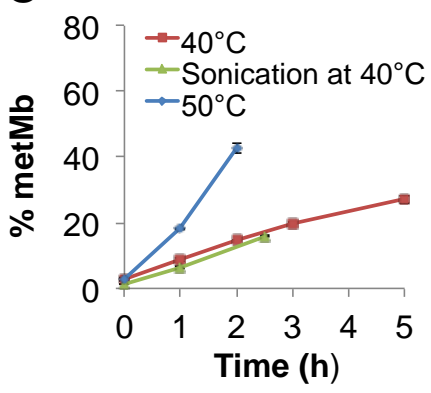

E

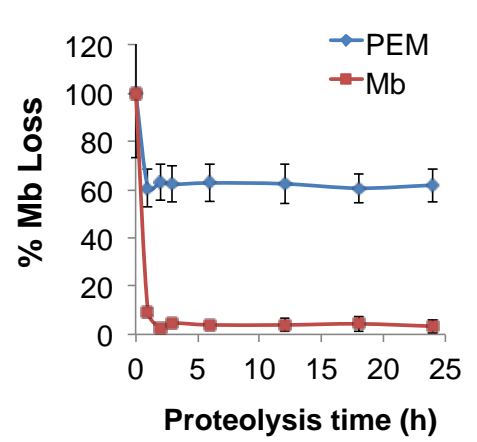

B

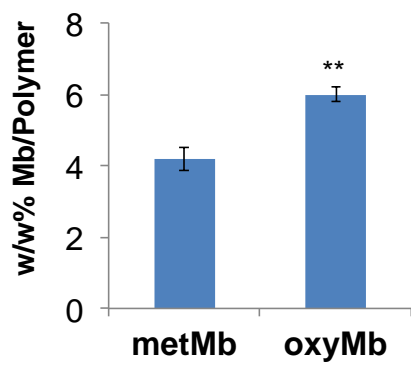

D

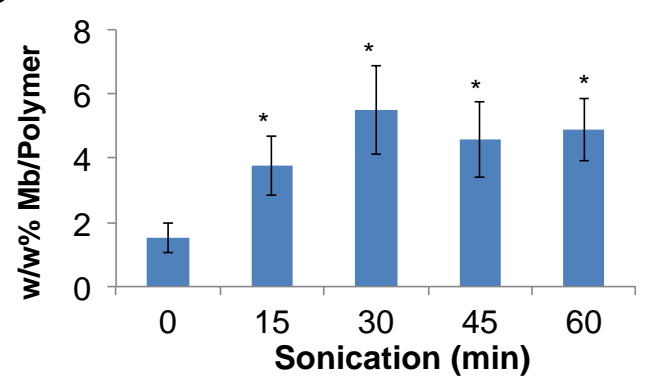

$\mathbf{F}$

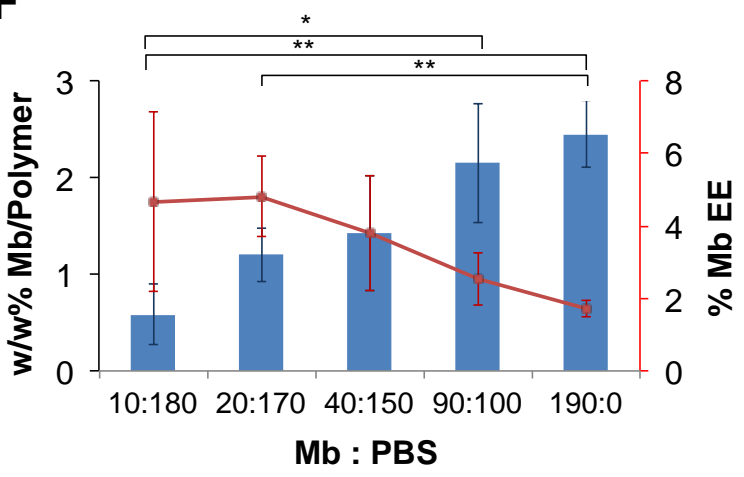

Figure 2. Optimization of various steps in the "direct hydration" protocol in order to improve the encapsulation of $\mathrm{Mb}$ in OB18 polymersomes (as determined by the final weight percentage of Mb-topolymer (i.e. w/w\% Mb/polymer) that could be obtained in PEM suspensions). A) The effects of utilizing an organic solvent vs. the addition of heat during the first step of the "direct hydration" protocol. B) The effects of the oxidation state of $\mathrm{Mb}$ used for polymersome encapsulation and for each subsequent addition step. $\mathrm{C}$ ) The rate of $\mathrm{Mb}$ oxidation (as expressed by the percentage of metmyoglobin (i.e. \%metMb) formed over time) as a function of $\mathrm{Mb}$ exposure to different solution conditions. $\mathrm{D}$ ) The effects of sonication time after each dilution step. E) Optimization of the proteolysis time to remove all surface-associated $\mathrm{Mb}$ from polymersome suspensions; note: "\% Mb loss" denotes surface-associated $\mathrm{Mb}$ fraction and not total $\mathrm{Mb}$; samples were proteolyzed for $18 \mathrm{~h}$ to remove surface-associated $\mathrm{Mb}$ followed by UV-Vis quantification. F) Final weight percentage of Mb-to-polymer (i.e. "w/w\% $\mathrm{Mb} /$ polymer") vs. Mb encapsulation efficiency (i.e. "\%Mb EE") obtained by tuning the relative volume of $\mathrm{Mb}$ suspension (150 $\mathrm{mg} / \mathrm{mL} \mathrm{Mb}$ ) to PBS used in each addition step. Data represent mean values and error bars denote standard deviations of the mean for an $n=5$ experimental replicates. $\left({ }^{*} p<0.05\right.$ and $* * p<0.01)$. 


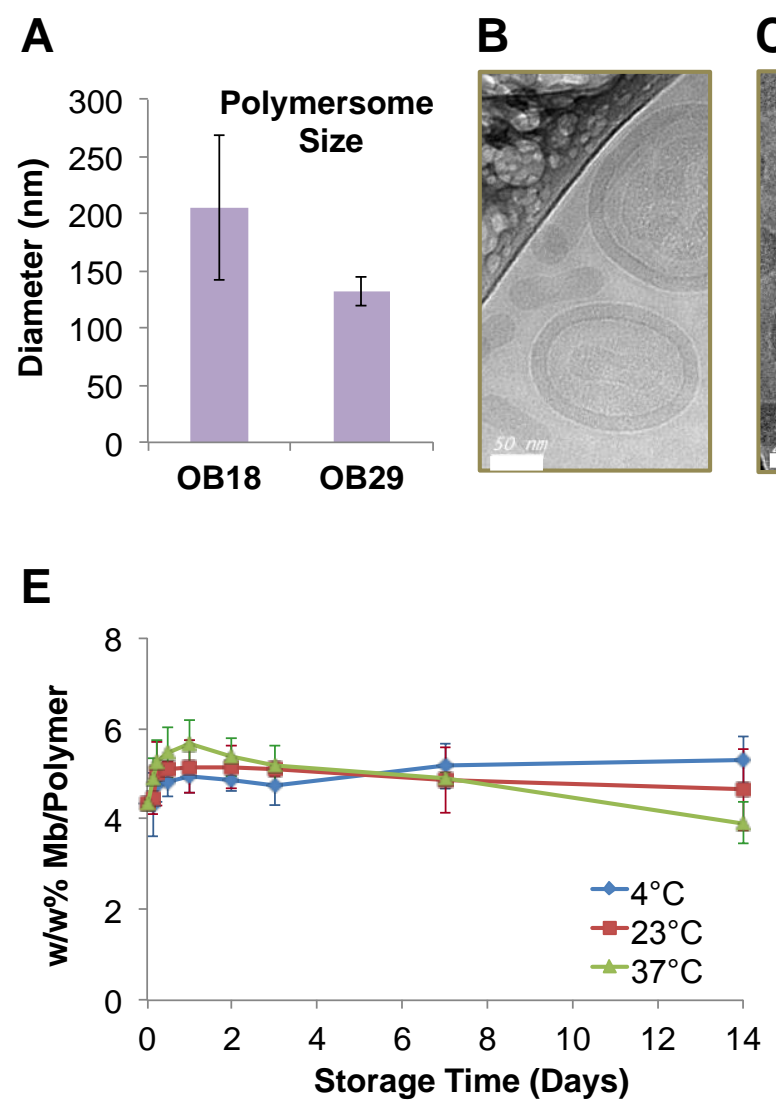

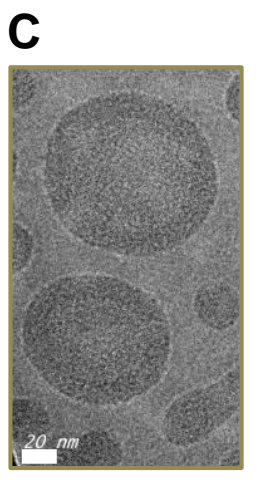
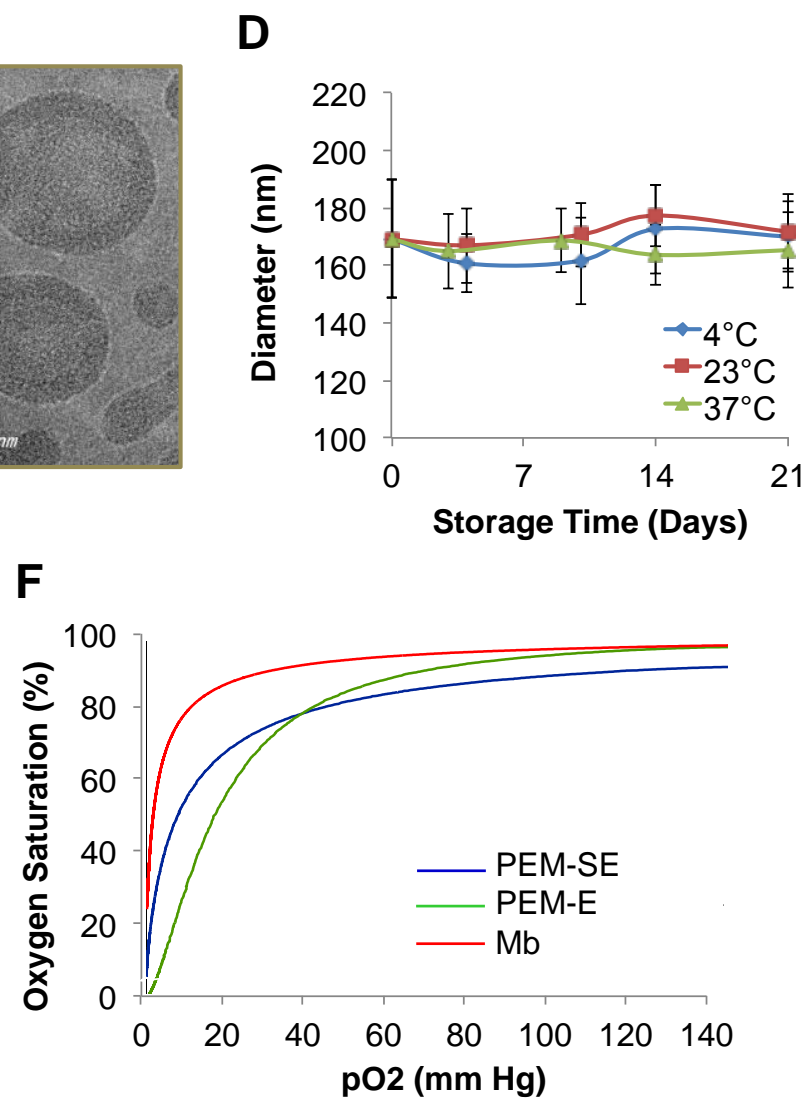

Figure 3. Characterizations of the final polymersome-encapsulated protein suspensions formed by using the "progressive saturation" technique. A) The average hydrodynamic diameter of particles in OB18and OB29-based PEM suspensions as assessed by DLS. Cryo-TEM images of vesicles in B) OB18- and C) OB29-based PEM suspensions; scale bar $=50$ and $20 \mathrm{~nm}$ in Fig. 3B and 3C, respectively. D) Average hydrodynamic diameters of particles (as determined by DLS) in OB18-based PEM suspensions as a function of temperature $\left(4,23\right.$, and $37^{\circ} \mathrm{C}$ ) and time. E) Final weight percentage of Mb-to-polymer (i.e. "w/w\% Mb/polymer") of particles in OB18-based PEM suspensions as a function of temperature $(4,23$, and $37^{\circ} \mathrm{C}$ ) and time. F) Oxygen equilibrium curves for free oxyMb and oxygenated OB18-based PEM suspensions. Data represent mean values and error bars denote standard deviations of the mean for an $\mathrm{n}=5$ experimental replicates. 


\section{SUPPORTING INFORMATION:}

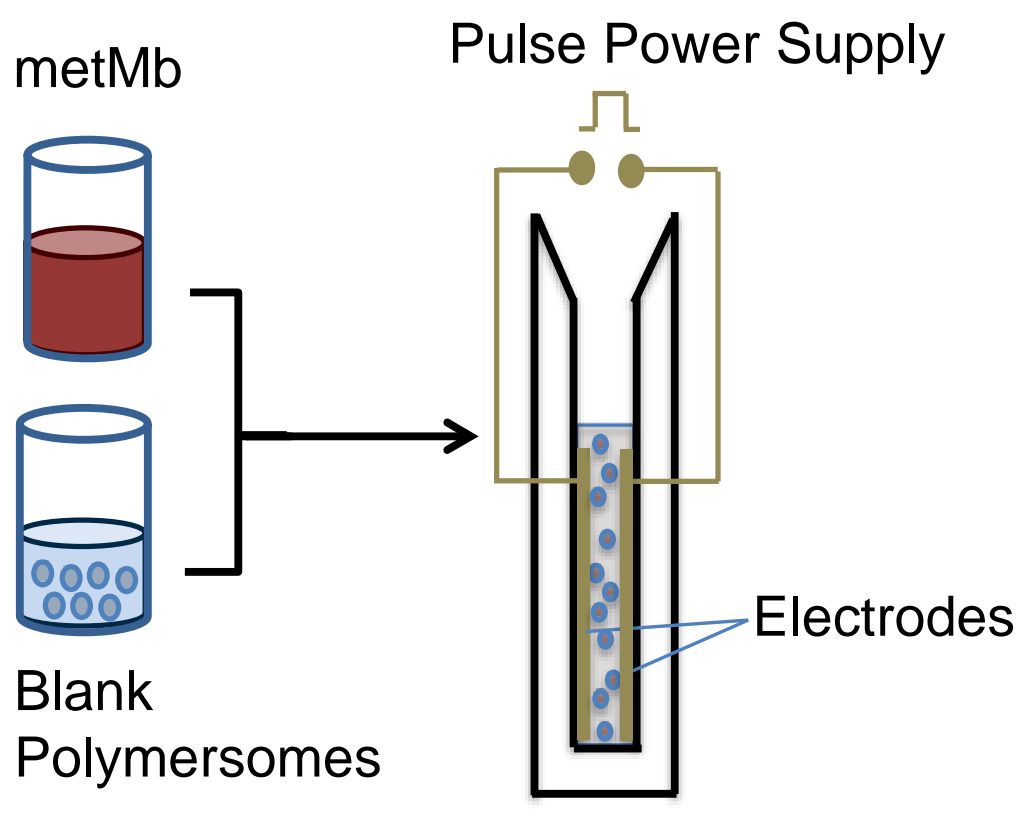

Scheme S1. Aqueous encapsulation of water-soluble species in polymersomes by "electroporation".

\section{Encapsulation of $\mathrm{Mb}$ using “electroporation"}

Preformed OB18-based polymersomes were prepared using "thin-film rehydration" and mixed with Mb solutions $(150 \mathrm{mg} / \mathrm{mL} \mathrm{Mb})$. The suspensions were subsequently loaded into $400 \mu \mathrm{L}$ cuvettes and subjected to electromagenetic fields, using an electroporation apparatus (applied voltage: 1.0, 2.0, or 2.5 $\mathrm{kV}$; output was a decaying exponential waveform with RC time constant of $5 \mathrm{~ms}$; the number of pulses equaled 20). The samples were dialyzed for $40 \mathrm{~h}$ at $4{ }^{\circ} \mathrm{C}$ to remove free protein $(\mathrm{MW}$ cutoff $=1000 \mathrm{kDa})$. $\mathrm{Mb}$ encapsulation in polymersomes was measured using UV-Vis spectrophotometry and was found to be negligible (results not shown). 